\title{
e-Leadership through strategic alignment: an empirical study of small- and medium- sized enterprises in the digital age
}

\author{
Weizi Li ${ }^{1}$, Kecheng Liu' ${ }^{1}$, Maksim Belitski ${ }^{2}$, Abby Ghobadian², Nicholas 0'Regan ${ }^{3}$ \\ ${ }^{1}$ Informatics Research Centre, Henley Business School, University of Reading, Reading, UK; \\ ${ }^{2}$ Leadership, Organisations and Behaviour, Henley Business School, University of Reading, Reading, UK; \\ ${ }^{3}$ Bristol Business School, University of West England, England, UK
}

\section{Correspondence:}

A Ghobadian, Leadership, Organisations and Behaviour, Henley Business School, University of Reading Greenlands, Henley-on-Thames, Oxfordshire RG9 3AU, UK.

Tel: +44 (0) 1491 418756;

E-mail: abby.ghobadian@henley.ac.uk

\section{Abstract}

Small- and medium-sized enterprises (SMEs) play an important role in the European economy. A critical challenge faced by SME leaders, as a consequence of the continuing digital technology revolution, is how to optimally align business strategy with digital technology to fully leverage the potential offered by these technologies in pursuit of longevity and growth. There is a paucity of empirical research examining how e-leadership in SMEs drives successful alignment between business strategy and digital technology fostering longevity and growth. To address this gap, in this paper we develop an empirically derived e-leadership model. Initially we develop a theoretical model of e-leadership drawing on strategic alignment theory. This provides a theoretical foundation on how SMEs can harness digital technology in support of their business strategy enabling sustainable growth. An indepth empirical study was undertaken interviewing 42 successful European SME leaders to validate, advance and substantiate our theoretically driven model. The outcome of the two stage process - inductive development of a theoretically driven e-leadership model and deductive advancement to develop a complete model through in-depth interviews with successful European SME leaders - is an e-leadership model with specific constructs fostering effective strategic alignment. The resulting diagnostic model enables SME decision makers to exercise effective e-leadership by creating productive alignment between business strategy and digital technology improving longevity and growth prospects.

Journal of Information Technology (2016) 31, 185-206. doi:10.1057/jit.2016.10

Keywords: e-leadership; small- and medium-sized enterprises; strategic alignment; organisational change; digital technology

The online version of this article is available Open Access

\section{Introduction}

Q mall and medium sized enterprises play an important role - within the European Union (EU) economy and the United - Kingdom is no exception. Not surprisingly, success and failure of SMEs has been studied extensively with the aim of identifying contributory factors, for example, strategic planning (O'Regan and Ghobadian, 2005a). E-leadership and its potential contribution to the success of SMEs is an area where the research evidence is light. We aim to fill this gap, not least because the dawn of the digital age has dramatically altered the rules of the game enabling firms to reach markets and customers directly through multi-channels and platforms (Cohen and Schmidt, 2013). The digital era is creating new opportunities, rendering the capability to effectively harness and utilise information technology (IT) critical to a firm's survival and prosperity. Key technologies with the potential to change the basic tenet of competition and reshape traditional industries include cloud computing, social media, the internet of things, mobile computing and big data analytics (LEAD, 2014). Such technological developments will speed up and improve the way new innovative products and 
services are conceived, developed, produced and accessed (Yoo et al., 2010).

Within the EU, SMEs account for $99.8 \%$ of all enterprises (Wymenga et al., 2012). In the United Kingdom, at the start of 2013, there were 4.9 million SMEs (99.9\% of all private businesses) (Department for Business Innovation \& Skills, 2013). UK SMEs employed 14.4 million people and accounted for more than half of the UK's private firms' turnover (Department for Business Innovation \& Skills, 2013; Lukács, 2005). The majority of new jobs in the United Kingdom have been created by small firms employing fewer than 50 people (Anyadike-Danes et al., 2013). On average, between 1998 and 2010, small firms generated $34 \%$ of 2.61 million new jobs (approximately 870,000 jobs) in the United Kingdom, while start-ups (nine out of ten have fewer than five employees) accounted for 33\% of these jobs (Anyadike-Danes et al., 2011). The digital age offers SMEs significant opportunities to develop entirely new high-value products and services, add value to existing products and services, reduce costs, develop new export markets and add value to existing activities (e.g., cloud computing, the internet of things, etc.). The transformation of the business environment by digital technologies is disrupting the existing order - opening opportunities for new entrants and new product markets with SMEs playing a pivotal enabling role (Deloitte, 2013).

However, failures of SMEs are frequent and are often thought to be because of management and leadership weakness (Avolio et al., 2001; ACCA, 2012; Arham et al., 2013). The virtual marketplace is rapidly fostering the growth of new business models, as well as dictating frequent renewal of existing business models and value chains (O'Regan and Ghobadian, 2005b). In the digital era, SMEs' inability to align business and technology strategy is a major hindrance to their survival and growth (Welsum and Lanvin, 2012). On the other hand, evidence suggests leadership and alignment can improve SMEs' success (Ghobadian and O'Regan, 2002; O'Regan and Ghobadian, 2004). One of the main challenges that SME leaders face today is how to optimally integrate business and information technology systems within their organisations to fully leverage the potential of digital technologies (Ferneley and Bell, 2006). Not surprisingly, SME leaders capable of effectively aligning business and digital strategy are more likely to succeed. However, to the best of our knowledge, there is little research examining how e-leadership within SMEs drives the successful alignment between business needs and technology innovation in pursuit of enhanced competitiveness. This alignment thinking is important for effective e-leadership and for successful implementation of digital projects (Avolio et al., 2001, 2014).

In the absence of well-articulated e-leadership theory, we adopt strategic alignment as the theoretical foundation to aid the initial development of our e-leadership model. Strategic alignment theory illustrates the dynamic alignment between businesses needs and digital technologies, emphasising both strategic and structural alignment. In this paper we develop an e-leadership model, drawing on theoretical lenses of strategic alignment and proceed to validate this model using a qualitative - explorative approach. We have conducted 42 interviews exploring the construct of e-leadership and how successful SMEs achieve effective strategic alignment through e-leadership. By combining theoretical propositions and empirical analysis, we develop an e-leadership model demonstrating how SME leaders can leverage business and digital alignment to unleash the potential of digital technologies.

The study combines inductive and deductive research. Initially we developed an e-leadership domains and capabilities framework drawing on strategic alignment theory. In the deductive phase of research we test the validity of our theoretically driven model and refined it by conducting 42 in-depth interviews with leaders of successful European SMEs operating in five European countries across different industries (including ICT and non-ICT SMEs). The choice of in-depth interviews rather than a survey was dictated by a lack of established constructs. This research is based on the project 'LEAD e-Leadership Skills: for Small and Medium Sized Enterprises' funded by the European Commission DG ENTR - Unit ENTRE4 - Key Enabling Technologies and Digital Economy (LEAD, 2014). The primary aim is to develop targeted actions for startups and fast-growing SMEs developing their relevant e-leadership skills. This research contributes to both e-leadership theory and managerial practice in SMEs. Drawing on strategic alignment theory, we construct an e-leadership model delineating domains and capabilities. The validity of this model was tested in the field and refined where appropriate. From a practical stance, the empirical phase of the research offered encouraging signs demonstrating that the application of the model improved the effectiveness of e-leadership facilitating closer alignment between business and digital technology strategy.

This paper is structured as follows: The section 'e-leadership foundations' reviews leadership in enterprise systems as well as the e-leadership concept at micro, meso and macro levels, followed by strategic alignment theory as the theoretical underpinning for e-leadership domains and capabilities. The data collection and analysis process is discussed in the section 'Methods'. Then, in the section 'e-leadership qualities and strategic alignment: empirical findings', we present our empirical findings followed by a more reflective synthesis in the section 'The development of an e-leadership model for SMEs'. Finally, in the section 'Conclusions and future work', we summarise and discuss our results, contribution and offer avenues for future research.

\section{e-Leadership foundations}

In this section we start with an overview of key applications of digital technology - enterprise systems and enterprise social systems - with a focus on the role of leadership (the section 'Leadership in enterprise systems' and 'Leadership in enterprise social systems'). The e-leadership concept is discussed in the section 'The emergence of e-leadership' at different levels, micro, meso and macro in the section 'e-leadership concept at micro and meso level', followed by identification of gaps in the current literature - at macro and strategic levels in the section 'e-leadership concept at macro level'. Our research will fill this gap at a macro level based on strategic alignment theory described in the section 'Strategic alignment theory', from which we developed the theoretical e-leadership exercising capabilities framework (Table 1) to guide the empirical investigations.

Leadership is about the leader's ability to mobilise followers towards a particular goal. On the basis of behavioural types, leaders are divided into two categories: transactional or transformational (Ke and Wei, 2008). Transactional leaders are sensitive to the needs of others, who, in turn, follow them in order to satisfy these needs (Jung and Avolio, 1999; 
Table 1 E-Leadership domain and capabilities framework (Adapted from Henderson and Venkatraman, 1993)

\begin{tabular}{|c|c|c|c|}
\hline $\begin{array}{l}e \text {-Leadership } \\
\text { critical decision } \\
\text { domains and } \\
\text { capabilities }\end{array}$ & $\begin{array}{l}\text { Domains of } \\
\text { decision } \\
\text { making }\end{array}$ & Details & e-Leadership capabilities \\
\hline
\end{tabular}

Strategy The business strategy has been articulated

execution and is the driver of both organisational

alignment design choices and the design of IS infrastructure

Technology Identify the best possible IT competences as transformation alignment well as corresponding internal IS
to implement businesses strategy

Competitive potential alignment

Exploitation of emerging IT capabilities to impact on new products and services, influence key attributes of strategy and develop new forms of relationships

Service-level

Understanding of IT strategy with alignment corresponding internal design of IS infrastructure and business processes
Strategy formulator to articulate the logic and choices pertaining to business strategy Strategy implementer to design and implement the required IS infrastructure and processes that support the chosen business strategy

Technology vision to support the chosen business strategy

Technology architect to design and implement the required IS infrastructure consistent with IT vision

Business visionary to articulate how the emerging IT competences and governance patterns would impact on business strategy Catalyst to identify and interpret trends in the IT environment to assist business managers to understand opportunities and threats from an IT perspective

Prioritiser to articulate how best to allocate scarce resources both within the organisation and in the IT marketplace Executive leadership to make the internal service business succeed within the operating guidelines from top management
Waldman et al., 2001). By contrast, transformational leaders are those who are capable of having profound and extraordinary effects on followers by the force of their personal abilities (House, 1971). Because they can appeal to their followers' emotions, transformational leaders motivate their followers to efforts that 'go above and beyond' the instrumental returns promised/delivered by transactional leaders (Klein and House, 1995; Podsakoff et al., 1997).

The emergence of digital technologies has changed the rules of the game to the point where the leadership needs to coevolve with the development of the organisation. Digital technology has changed boundaries, economies of scale and scope, the value-capture rules and provider - user interaction. Put simply, digital technology is increasingly delivering boundaryless organisational structures and a collaborative business environment. Leadership plays an important role in the successful adoption of digital technology.

\section{Leadership in enterprise systems}

Enterprise systems enable the integration of transactionoriented data and business processes throughout an organisation and potentially throughout the entire inter-organisational supply chain (Markus and Tanis, 2000). Enterprise systems include enterprise resource planning (ERP) software and such related packages as advanced planning and scheduling, sales force automation, customer relationship management and product configuration. They emerged in the 1990s and provide capability in support of business growth and improved competitiveness by integrating business processes and reducing cost.

However, empirical studies indicate that firms have found it difficult to successfully implement enterprise systems resulting in lower than expected gains in competitiveness (Dong et al., 2009). For example, Standish Group International (2006) reported that only $35 \%$ of companies in the United States completed their information systems (IS) implementation on time and within budget. Incidences of underperformance and failure are as high as $90 \%$ (Loonam and McDonagh, 2004) with up to $50 \%$ of IS initiatives being abandoned or failing outright, with an additional $40 \%$ of IS initiatives being delivered late and over budget. The primary cause of lower than expected gains is poor alignment between business needs and technology (Bloch et al., 2012). The high-performing enterprise system team usually establishes a clear view of the initiative's strategic value - one that goes beyond the technical content. They make sure the project aligns with the company's overarching business strategy and undertake detailed analyses of stakeholder positions (Bloch et al., 2012).

The extant literature suggests that leadership and top management support is one of the most critical success factors. Furthermore, scholars argue that leadership plays a critical role in effective implementation of enterprise systems and organisational culture change (Armstrong and Sambamurthy, 1999; Waldman et al., 2001; Vera and Crossan, 2004). Leaders (e.g., CIOs and senior managers) perform the crucial functions of transformational leadership, facilitation and marketing the project to the users (Akkermans and van Helden, 2002). 
In particular, IS literature suggests that leaders' vision, attitude and behaviour significantly influence employees' perceptions of the benefits of IT innovation, and hence its adoption outcomes (Orlikowski, 1992; Boynton et al., 1994; McKenney et al., 1997; Purvis et al., 2001). As far as ERP implementation is concerned, leadership is consistently identified as the main determinant of successful ERP implementation (Bingi et al., 1999; Al-Mudimigh et al., 2001; Umble et al., 2003). Leadership support leads to increased system usage (Bardi et al., 1994; Guimaraes and Igbaria, 1997), positive user perceptions (Igbaria et al., 1997), improved IT adoption and diffusion (Ramamurthy and Premkumar, 1995; Bruque-Camara et al., 2004) and better performance (Bardi et al., 1994). Furthermore, leadership facilitates smooth change management (Bingi et al., 1999). Leadership can also be seen as the propagated approach of individuals and champions who can effectively implement change programmes such as enterprise social systems (Al-Mashari et al., 2001).

\section{Leadership in enterprise social systems}

With business today moving at an accelerated pace, the need for enterprise social networking is greater than ever. Current communication software and enterprise systems such as ERP, customer relationship management (CRM) and supply chain systems don't support the collaboration required to speed up critical processes (Vmware, 2013). Communications still remain fragmented as users try to communicate and collaborate in a piecemeal fashion. Digital technologies, by combining social technologies with data analysis and mobile technologies, are enhancing organisations' ability to connect with key direct stakeholders (customers, suppliers), respond more quickly and effectively to market changes, enable employees to work on the tasks that most benefit the organisation at any given point in time, and deploy multi-channels and platforms (McKinsey, 2012). Enterprise social systems then emerge by integrating technologies such as social media into the regular workday experience to promote employee collaboration, productivity and innovation. The benefit of enterprise social systems is 'sharing information', a key to employees 'thriving', as opposed to merely being 'satisfied'. Enterprise social systems provide a repository for and access to corporate knowledge, accelerated R\&D-led innovations, improved decision-making and even increased employee morale, which are essential for SME growth.

However, in reality, organisations tend to focus on providing a communication technology platform rather than delivering a social solution that targets specific business value (Gartner, 2010). Instead, the real value-adding opportunities of social technologies lie in exploiting their capabilities to reshape organisations' business models. This is where the failure to deliver surfaces in many organisations (Willcocks and Sykes, 2000). Improving business competitiveness is more than just implementing technology; it is about parallel introduction of major human, cultural, and organisational changes. Therefore a successful enterprise social system is more about the transformation of the culture, strategy, skills and processes - where all of these work together as an integral social system.

Leadership is regarded as the key driver in aligning enterprise social systems to business goals (Sarker and Lee, 2003). Effective leadership will drive the rethinking of how business is done by letting enterprise social systems permeate business processes rather than exist in parallel with them. Therefore SME leaders should be able to bring on enterprise social technologies to support every aspect of business practice. Though leadership has been identified by many researchers as one of the key factors in the success of enterprise systems, there is a paucity of research on how specifically leadership drives business success through technology. Dong et al. (2009) identified three types of top management support in successful IS implementation. The first type of support is resource provision to supply key resources such as funds, technologies, staff and user training programmes. The second type refers to change management to foster organisational receptivity of a new IS. The third type of support is vision sharing related to ensuring that lower level managers develop a common understanding of the core objectives and ideals for the new system. The behaviours (or non-behaviours) of top managers have a direct influence on IS implementation outcomes and leaders need to actively exhibit supportive actions to ensure that strategic visions are internalised. As enterprise system implementations tend to introduce foreseeable and unforeseeable organisational changes (Davenport, 1998; Markus and Tanis, 2000), leaders need to adapt the content of support to fit what is needed at different stages of 'readiness' in implementing the enterprise social system (Roberts et al., 2003). The visibility of leadership throughout the entire process of implementing enterprise systems is also important to publicly demonstrate leaders' determination, vision and appreciation via a steady execution of concrete action and communication (Fox and Amichai-Hamburger, 2001). Furthermore, leadership also plays an important role in building key in-house IT capabilities prior to introducing an enterprise social system. Willcocks and Sykes (2000) have identified IT leadership as one of the most important in-house IT capabilities. Leaders must behave as knowledgeable strategic executors and be able to align investments in IT with strategic business priorities. The focus of the current research is on leadership associated with implementing large-scale information systems (e.g., ERP). Very little research has focused on how leadership drives success in the digital age by embracing social systems. There are significant differences between large businesses and SMEs (Ghobadian and Gallear, 2001). Hence it is important to examine the relationship between leadership, business strategy and technology in the digital age. The research presented in this paper addresses this gap by investigating how effective e-leadership maximises business competitiveness of SMEs in the digital age. In the following section we examine the e-leadership concept from different perspectives and highlight the focus of our research exploring the strategic role of e-leadership in building competitive capabilities.

\section{The emergence of e-leadership}

Leadership in the digital age has morphed into 'e-leadership', defined as a social influence process embedded in both proximal and distal contexts mediated by digital technology that can produce a change in attitudes, feelings, thinking, behaviour and performance (Avolio et al., 2001, 2014). e-Leadership takes shape in a virtual context where collaboration and leader - follower interaction are mediated by ICT, and it aims to create and distribute the organisational vision and to 'glue' corporations or individuals together, as well as 
direct and supervise the execution of plans (Avolio and Kahai, 2003).

Theoretical suggestions that leadership and technology influence each other date back to 1990, as emphasised by Weick (1990), Orlikowski et al. (1995) and Avolio and Gardner (2005). In particular, adaptive structure theory (AST; DeSanctis and Poole, 1994) has been used by Avolio et al. (2001) as a foundational theoretical framework to examine e-leadership, especially in determining how the appropriation of information by leaders and their peers or followers can affect how those leaders lead through technology, and how leadership itself affects the use of technology. With the emphasis placed on what constitutes the source of e-leadership and how the source of leadership is transmitted when it is mediated through digital technologies, e-leadership can be studied at meso, micro and macro levels. We will introduce these three levels in the following sections but with a focus on e-leadership at the macro level where our research in this paper resides.

\section{e-Leadership concept at micro and meso level}

The e-leadership focus at the micro level is primarily on distant communication with virtual teams and communication skills in the technology-mediated environment (Gurr, 2004; Malhotra et al., 2007; Avolio et al., 2009). e-Leadership is mainly studied as the management of distributed teams whose members predominantly communicate and coordinate their work through electronic media (Kerfoot, 2010). Leaders' behaviour at geographical distance is also studied to see if the traditional core set of leadership behaviours is effective in the distributed working environment and how those behaviours impact on the team's performance (Watson, 2007).

e-Leadership at a micro level can originate from individuals assuming the role of leader and/or follower, leader - follower dyads with members operating in a virtual group, or within the context where these entities are embedded. According to Avolio et al. (2014), recent trends in social media, mobile, big data analytics, cloud computing and the internet of things have broadened both the range of micro-organisational behaviour sources of e-leadership influence and the way in which it is transmitted and received by those involved in its interactive and dynamic processes. Features of digital technology can either enhance or diminish the effects of leaders and followers exerting e-leadership influence depending on the source of e-leadership, its mechanisms for transmission and the technology being used (Kahai et al., 2013). According to Hernandez et al. (2011), e-leadership can be transmitted (similar to leadership in the face-to-face context) via the traits (i.e., who one is), behaviours (i.e., what one does), cognitions (i.e., what and how one thinks) and affects (i.e., what one feels) associated with leaders and followers. Each of these mechanisms provides a unique way for leadership influence to be transmitted and received by others and offers implications for e-leadership theory. On the other hand, e-leadership at a meso level is described as changes occurring at work and how they are influencing the loci and mechanisms of leadership. The changes include increasing use of information in organisations, greater transparency and openness, the rise of social networks, constant contact and increased use of tracking devices (Kahai et al., 2013; Avolio et al., 2014).
$e$-Leadership concept at macro level

Our research will focus on the e-leadership concept at a macro level. At a macro level e-leadership refers to strategic implications of e-leadership in organisational change and transformation (Avolio et al., 2014). The strategic implication refers to strategic change and transformations in organisations, as well as how organisations relate to each other within and between markets. The strategic implication is addressed by the IT, organisational theory and leadership literatures (Henderson and Venkatraman, 1992). Despite this burgeoning literature there is a paucity of sound theoretically based empirical research examining the role of e-leadership and digital technology in facilitating or inhibiting organisational change, and its impact on leadership and organisational transformation.

Henderson and Venkatraman (1992) were among the first authors to discuss the need for strategic alignment between IT implementation and organisational change. The extant literature suggests that investing in IT as part of the organisational change process is an important asset for leveraging organisational change (see, for example, Holt et al., 2007; Gilley et al., 2009). Besson and Rowe (2012) conducted a 20-year review of the literature on IT-enabled organisational transformation, concluding that relatively little attention was paid to examining the effects of leadership on such transformation. To this end Avolio et al. (2014) concluded that we still know very little about how e-leadership, information technology and their interaction affect strategic leadership and organisational transformation.

To address this theoretical and empirical gap we focus on e-leadership at the macro level paying particular attention to strategic alignment. The aim of this paper is to develop and empirically test an e-leadership conceptual model focusing on how leadership in SMEs leverages business and digital technology by addressing the following two critical questions: (1) What are the e-leadership constructs contributing towards effective strategic alignment? and (2) What leadership practices do successful SMEs engage in to leverage the benefits of IT? We contribute to the literature through in-depth exploration of different dimensions of e-leadership constructs and how they interrelate to achieve effective strategic alignment.

\section{Strategic alignment theory}

To drive the empirical stage we conducted a detailed literature review with the aim of identifying relevant theories/models of alignment between strategy and IS/digital technology. Our extensive literature search failed to unearth theories/models addressing alignment between strategy and digital technology. On the other hand, we identified a potentially relevant theory/ model addressing alignment between businesses and IS strategy, namely, strategic alignment theory. As was mentioned, alignment between business and IS strategies is essential in realising full value from IS investment (Henderson and Venkatraman, 1993; Coltman et al., 2015). The extant empirical research supports this point and shows that strategic planning and alignment enhance the competitiveness of SMEs (Ghobadian and Gallear, 2001; O’Regan and Ghobadian, 2002). The notion of strategic alignment builds on three central arguments (Hirschheim and Sabherwal, 2001; Peppard and Breu, 2003). First, organisational performance depends on structures and capabilities that support the successful realisation of strategic decisions; second, alignment is a two-way process where 
business and IS strategies can act as mutual drivers; third, strategic IS alignment is not an event but a process of continuous adaptation and change' (Henderson and Venkatraman, 1993). It is reasonable to assume that these arguments equally, if not more so, apply to digital technology, which is inherently more pervasive and multi-layered.

The strategic alignment theory proposed by Henderson and Venkatraman $(1989,1993)$ points to the dynamic alignment between business and IS strategies, stressing the importance of both strategic and structural alignment. The aim is to explicitly identify the range of strategic choices in an organisation and their interrelationships with IS. In particular, the strategic and functional integration of both business and IS aspects constitute key alignment dimensions, which further lead to four domains of strategic choice: business strategy, organisational infrastructure and processes, IS strategy and IS infrastructure and processes. Effective management requires a balance among the choices made across all four domains. Effective e-leadership strives to attain close alignment by considering how choices made in the IS domain impact on (i.e., enhance or threaten) those made in the business domain and vice versa. Strategic alignment theory identifies the domains of decision-making and leadership capabilities required to attain close alignment. As shown in Table 1, the four domains critical to alignment between business and IT strategy are: strategy execution, technology transformation, competitive potential and service level. These four domains drive the e-leadership capabilities (Table 1). Managers through exercising these capabilities enhance the likelihood of alignment leveraging the benefit of digital technology in business competiveness. The e-leadership critical decision domains and capabilities, on one hand, address IS functionality to both shape and support business strategy where digital technology becomes an important source of strategic advantage. On the other hand, they deal with the criticality of ensuring internal coherence between the organisational requirements and delivery capability within the IS function.

The four domains described offer leaders a tool to align their business and digital (IT) strategy. The question is, how to conceptualise e-leadership that will effectively drive the above alignments? These alignment factors and their relationship in SMEs have rarely been empirically analysed and tested. The e-leadership domain and capabilities framework (Table 1) provides the theoretical basis for us to address this gap through an in-depth empirical study focusing on European SMEs operating in different sectors. Specifically, the e-leadership domain capabilities model will support the empirical investigation in the following ways (for a detailed discussion see the section 'Methods'). First, the four e-leadership domains will guide the codification process to classify data codes into categories and subcategories (the section 'Data analysis'), as well as development of the constructs, subcategories and categories that systematically interrelate towards the e-leadership model (the sections 'e-leadership qualities and strategic alignment: empirical findings' and 'The development of an e-leadership model for SMEs'). Second, e-leadership capabilities will guide the design of the interview protocol and interviewee selection criteria (the section 'Data collection') according to different capabilities of leaders (as shown in Table 1: strategy formulator and implementer; technology vision and architect; business visionary and catalyst; prioritiser and executive leadership).

\section{Methods}

To meet our aims we used a three-stage qualitative explorative research method. First, we conducted a comprehensive literature review to identify factors leading to success and/or failure of digital/IT technology implementations and identify appropriate theories/frameworks. Second, we examined the relevance of theories unearthed and adapted strategic alignment theory because of its clarity in identifying key integration domains and the appropriate leadership capabilities. This leads to the inductive development of the e-leadership domain and capabilities framework. Third, we conducted field work and analysed the data (see Figure 1). This stage involved deductive advancement through in-depth interviews to identify SME e-leadership qualities (Figure 2 in the section 'e-leadership qualities and strategic alignment: empirical findings') and constructs for each quality (Figure 3 in the section 'The development of an e-leadership model for SMEs'). The outcome of the analysis resulted in a comprehensive SME e-leadership model highlighting the key e-leadership capabilities necessary for effective alignment between business and digital strategy. The research process is depicted in Figure 1.

\section{Data collection}

The sample for this study was drawn from among SMEs operating in the United Kingdom, Spain, Demark and the Netherlands. SMEs are the life blood of the economy. Furthermore, SMEs are different to large organisations particularly when it comes to the implementation of new processes (Ghobadian and Gallear, 1997). The key differences are lack of slack resources (that is, available resources are scarce) resulting in a low tolerance of strategic mistakes, a narrower cognitive window and a more limited boundary-spanning horizon. The sample selection criteria were developed by the research grant holders as this paper is based on a European research project entitled: e-Leadership Skills for SMEs (LEAD, 2014). The team of researchers consisted of 20 consultants and academics from five European business schools (from Germany, Spain, Bulgaria, France, the United Kingdom and Denmark). The process for developing the selection criteria included a one-day workshop and three teleconference sessions. The final selection criteria were: (1) size of SMEs: firms with 10 to 250 FTEs employees as well as micro enterprises $(<10$ employees is exceptional, e.g. innovative business model and potential market); (2) the maturity stage of SME-gazelles (OECD, 2010): 'enterprises which have been employers for a period of up to 5 years with average annualised growth in employees (or in turnover) greater than $20 \%$ per year over a three-year period and with 10 or more employees at the beginning of the observation period'; (3) successful SMEs can be gazelles or be recognised by a well-regarded third party as successful (e.g., Thames Valley 100 best SMEs unveiled in Business Magazine in the United Kingdom). The reason we focus on successful SMEs is that we aim to explore best practices when building the diagnostic e-leadership model with successful companies that are aware of e-leadership and use it in their business to contribute to business competitiveness and growth.

Fifty EU SMEs were identified initially as potential candidates for the study of which 42 companies met the criteria and were therefore included in the study. These SMEs are from four EU countries: United Kingdom (12), Spain (10), 


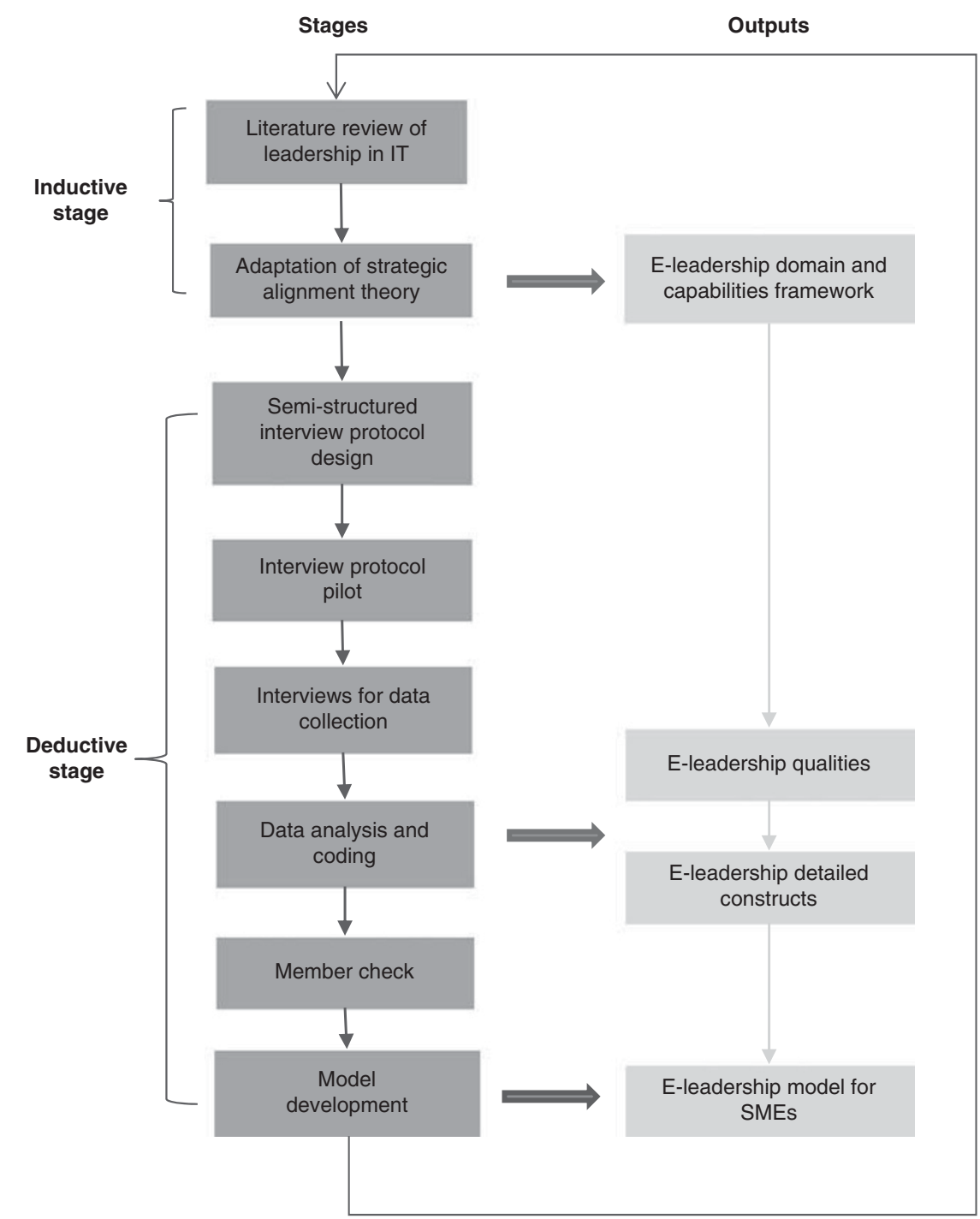

Figure 1 Research methodology.

the Netherlands (10) and Denmark (10). Furthermore, drawing on the concept of theoretical replication (Yin, 2009; Buchwald et al., 2014), we tried to achieve sufficient variation across the organisations with respect to industry and number of employees, as well as having the appropriate ratio of IT and non-IT companies to avoid bias in this regard. These companies range across different fields and industries (details in Appendix A). In particular, there are 19 IT related companies (comprising $45 \%$ of the sample) and 23 non-IT related companies (comprising $55 \%$ of the sample). The percentage of non-IT companies is slightly higher because evidence shows that firms whose main business is not IT or IT-related face different sets of challenges when it comes to the strategic use of IT than firms whose business is IT.

We aimed to interview the top and middle managers (e.g., CIO, CTO, CEO, IT directors deputy CEO) of these firms. We chose the interviewees by identifying key persons and decision makers who execute leadership for business and digitalisation strategies, in particular with a strategic alignment focus (see Table 1) on strategy execution, technology transformation, competitive potential and service management. More specifically, the interviewees were selected based on the various roles of strategic alignment according to Henderson and Venkatraman (1993). Therefore the top and middle managers, with the roles of strategy formulator and implementer; technology vision and architect; business visionary and catalyst (based on strategic alignment theory in Table 1), were selected as interviewees. The interviewees were recruited by means of invitation emails and 68 interviewees were recruited from the 42 companies. Eventually we conducted 42 interviews: 19 involving one interviewee; 20 involving two interviewees simultaneously; and three involving three interviewees simultaneously. The 42 interviews were conducted between February and October 2014.

The design of the interview protocol was guided by the e-leadership theory presented previously (Table 1). As was noted, the theory and model were adapted to align with the SME context. The interview protocol consisted of five main parts: background and overview of the successful SME, demand for e-skilled professionals, overview of a significant innovation from the past year, future demand for e-leaders 


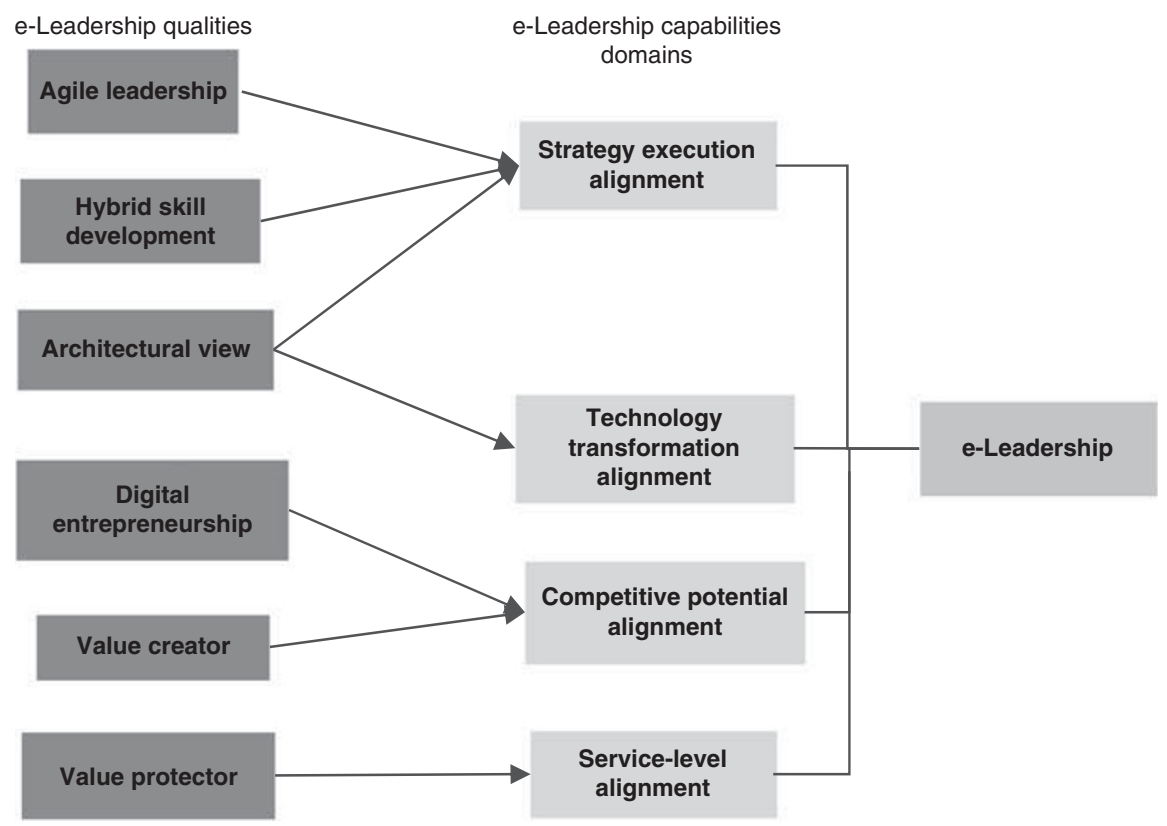

Figure 2 e-Leadership qualities in strategic alignment.

and engagements with educational institutions. These resulted in 24 questions. The detailed questions in 'e-skilled professionals, overview of a significant innovation, and future demand for e-leaders' were designed with the focus on e-leadership capabilities (see Appendix B). We pre-tested the interview protocol by holding four sessions within the project team and included an SME top manager to provide external feedback. Before the interviews, pilot interviews were conducted in February 2014, with both IT and non-IT companies, to test the understanding of and relevance of questions and the e-leadership model. The interviewees were informed of the length of the interview ( $1.5 \mathrm{~h}$ ) beforehand in order to address time constraints and increase the likelihood of cooperation. Furthermore, in order to ensure consistency in understanding of e-leadership between interviewers and interviewees and to avoid misunderstandings and ensure validity of content, we asked the participants for their understanding of e-leadership. During each interview we compared the interviewee's understanding with our initial e-leadership and strategic alignment definition and used the interviewee's answers to steer the conversation picking up on emergent themes and aspects specific to the interviewee. All the interviews were then transcribed and stored in a database.

\section{Data analysis}

We began the data analysis by identifying the concepts that either contributed to business success through e-leadership or caused problems that the firms had to overcome, as well as the impact of e-leadership on strategic alignment within our sample of SMEs. Furthermore, we searched for similarities and differences between the sample organisations, which enabled us to identify patterns that could potentially be included in an e-leadership model to explain its role in strategic alignment. The interviews thus helped us to gradually identify the constituent elements of the framework. Two researchers involved in this paper coded the interview transcripts. We started our data analysis with the theoretically highlighted e-leadership domain and capabilities framework (Table 1) for guidance. All the data was initially open-coded and then further analysed by dividing, comparing, forming and categorising the data into meaningful elements that support the theoretical framework (Saldaña, 2012). Thus we scanned the interview transcripts for similarities and differences and assigned codes to them. By merging analogous codes and resolving conflicting codes the constructs identified in the coding process were grouped into synthesising categories. We then condensed the codes resulting from the coding process into 6 categories and 16 subcategories.

Table 2 provides a summary of excerpts from the codes that were included in exemplary categories and subcategories. The categories and subcategories provide a basis for e-leadership qualities and specific constructs in the model. In order to derive the propositions in our model, we not only identified constructs in our transcripts, but also marked how these constructs relate to the theoretical e-leadership domain and capabilities framework. The empirical grounding of each proposition is thus provided alongside. A member check was also undertaken after completing the data analysis. The report on the results of our study with descriptive statistics and the proposed e-leadership model was presented at a project workshop held in Brussels in November 2014, where nine interviewees from four SMEs (two IT and two non-IT) were invited to attend. We received positive feedback, in particular on how the report and model supported their understanding of e-leadership.

\section{e-Leadership qualities and strategic alignment: empirical findings}

We draw extensively on interviewees' responses to describe the successful e-leadership characteristics contributing to effective strategic alignment. Guided by the e-leadership domain and capabilities in the section 'Strategic alignment 


\section{Constructs}

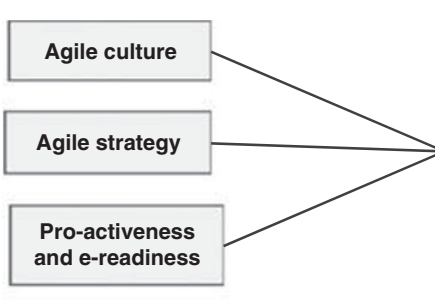

E-leadership qualities

E-leadership capabilities domains

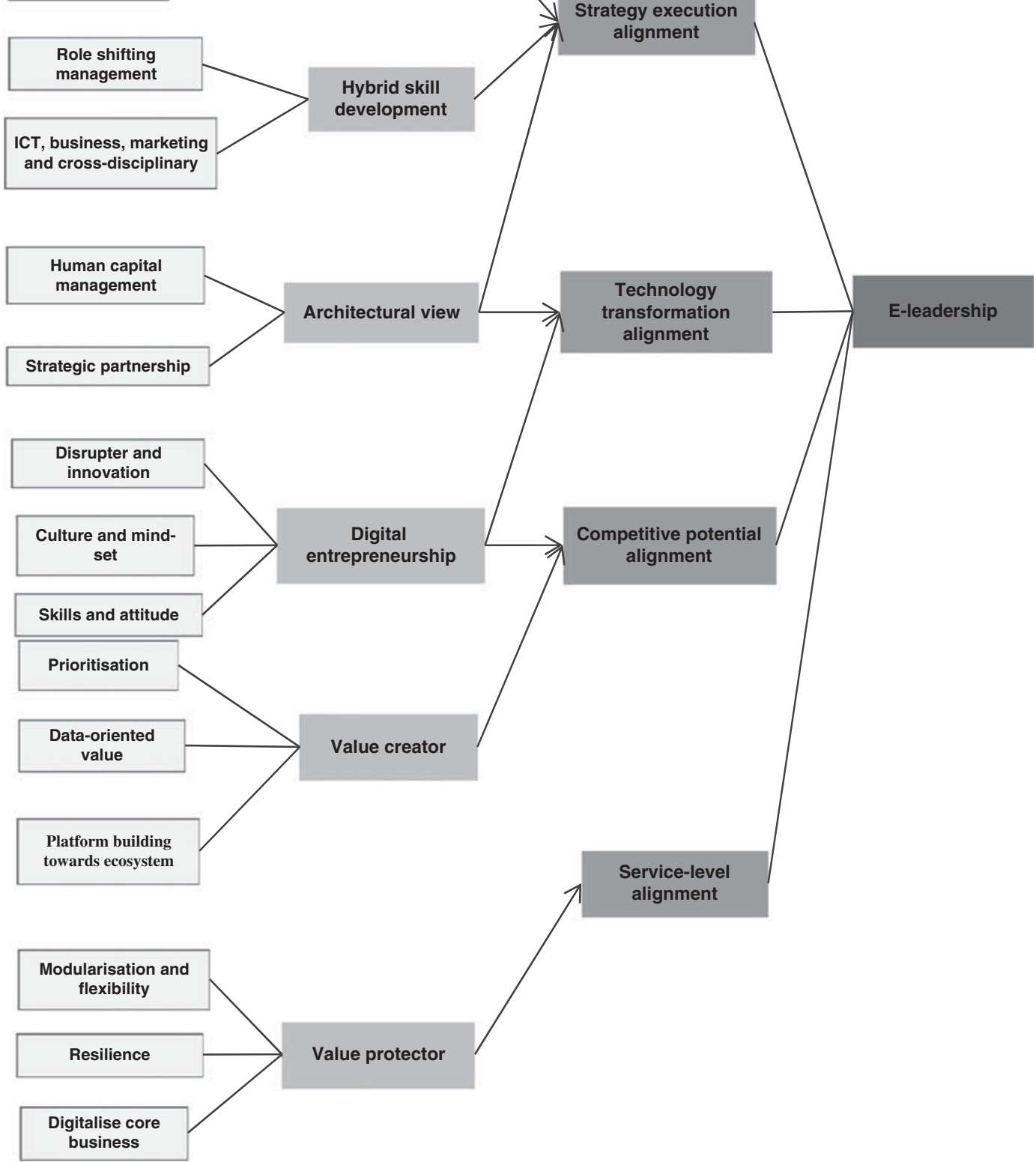

Figure 3 The e-leadership model for SMEs.

theory', we have delved deep into the data to develop a more profound understanding of e-leadership capabilities in strategy execution alignment, technology transformation alignment, competitive potential alignment and service-level alignment. As shown in Figure 2, six e-leadership aspects have been identified from the empirical data that have a relationship to strategic alignment perspectives. Propositions are made on how these aspects contribute to strategic alignment in e-leadership.
Qualities in strategy execution and technology transformation alignment

Agile leadership is the most frequently identified feature of e-leadership. Agility refers to a leader's quick response to opportunities and threats in a business environment using IT. Agile leadership in the digital age therefore refers to the ability of a leader to lead effectively in different circumstances especially new, changing and sometimes ambiguous situations 
Table 2 Sample categories of codes from interviews

\begin{tabular}{|c|c|c|c|}
\hline Theoretical e-leadership capability domain & Category (quantity) & Subcategories (quantity) & Code examples \\
\hline \multirow[t]{3}{*}{ Strategy execution alignment } & \multirow[t]{3}{*}{ Agile leadership (19) } & Agile culture (10) & $\begin{array}{l}\text { - Agile mindset } \\
\text { - Quick team building } \\
\text { - Clear vision and } \\
\text { collaboration }\end{array}$ \\
\hline & & Agile strategy (6) & $\begin{array}{l}\text { - Agile preparation of IT } \\
\text { infrastructure } \\
\text { - Quick prototyping strategy } \\
\text { - Lean innovation }\end{array}$ \\
\hline & & Pro-activeness (3) & $\begin{array}{l}\text { - e-Readiness on human } \\
\text { and IT systems } \\
\text { - Knowledge and skill for } \\
\text { future strategy } \\
\text { - Investment for future } \\
\text { expertise }\end{array}$ \\
\hline
\end{tabular}

with disruptive technologies. Thirty out of 42 interviewees indicate that CIOs and CTOs succeed or fail depending on their ability to exploit emerging digital capabilities in the creation of new products and services. Thus a leader's agility influences key elements of business strategy. Agility affects the efficiency and development of new products and enables managers to build relationships with customers and suppliers within vertical and horizontal value chains. Agile leadership enables alignment in strategy execution by quickly articulating and prototyping the strategy into business logic choices, as well as IS infrastructure and processes.

Interviewees stated that agility was linked to pro-activity and foresight in detecting changes in the environment. Skills, IS infrastructure, functions and processes required in articulating and prototyping the strategy were considered important in preparing SMEs to quickly respond to the changing environment. For example, a software firm alluded to the importance of investing in training and development, preparing and equipping staff to take advantage of future technologies. The firm supported and encouraged IT staff to attend international conferences and in-house training (seminars) to equip them with the necessary IT and marketing skills to respond to forthcoming technology and strategy. This investment in people is seen as important in maximising value in the future, especially when related IS strategy is implemented. A CEO of a finance organisation mentioned, 'we pro-actively work in association with a number of freelancers to develop the design of the IS infrastructure for them. Although this effort for readiness increases the workload prior to the implementation of business strategy, it leverages the contingencies and enables agile execution of business and IS strategy well in advance'. Therefore we propose:

Proposition 1: Agile leadership enables alignment in strategy execution by quickly articulating and prototyping the strategy into business logic choices as well as IS infrastructure and processes. Agile leadership enhances success in changing and sometimes ambiguous situations with disruptive technologies.

Hybrid skills were found to be important in strategy execution alignment to better exploit new technologies and embed them into the business model of the organisation.
It may be that 'native' digital enterprises (e.g., web entrepreneurs) have 'innate' e-leadership skills and leapfrog other firms employing IT innovation. Nevertheless, this does not mean that they are competent in integrating business and market knowledge with available IT or that they have a full range of embedded e-leadership skills. The hybrid skill embraces business, strategy and IT skills. The demand for hybrid skills is driven by the need to exploit IT in order to respond rapidly to market changes, digital patterns and new business opportunities. In particular, from the strategy perspective, firms need hybrid skills to develop new customers and retain existing ones. This will help firms to be more efficient in decision-making and new product development, understanding growth and digital patterns and defining priorities. From the sales perspective, firms need hybrid skills to grow sales, build 'data supply chains', negotiate with customers and suppliers of interim materials, and undertake business analytics. From the IT perspective, firms need hybrid skills to nurture and develop apps systems, optimise data storage and to exchange and link to customers through social media, maintaining privacy and cyber security of their data. Some interviewees commented on the implications of outsourcing. For example, in one case: 'in-house staff (project coordinators) to be more capable of querying delivery of solutions provided by the private sector'. This respondent noted that skills are lost because of outsourcing and with them an ability to respond to new technologies. It was highlighted that SMEs faced 'silos of knowledge - not specifically because information sharing is poor but because the organisation is small and we have specialists in individual areas'.

Eight out of 42 organisations highlighted leadership in 'understanding of the business and bridging the gap with the organisation's vision', and 'understanding of the business objectives driving IT choices'. The breadth of skills for leaders who can play multiple roles in a team and who have knowledge of different technologies to support business partners is important for both business-driven and ICT-enabled alignments (Henderson and Venkatraman, 1993). For instance, a CTO from the aerospace sector commented, 'better CEOs and other executives understand digital technology and its impact on organisations'. A CEO from cyber security noted the need for, 'quality managers who understand much more than 
simple economics - people are the key resource to be managed and encouraged, not beaten into submission'. A possible negative to the idea of the 'hybrid manager' arises from several participants pointing to the importance of IT people being properly involved in selling the organisational strategy and getting it over the line and into delivery.

The interviewees pointed out that the distinction between managerial leaders and IT leaders is likely to disappear over time. Managers, regardless of speciality, general or IT, need to understand the problems that customers face and offer appropriate solutions in terms of new or modified products, services or processes. Therefore technical leaders with organisational and IT skills could work on a broader basis, offering a wider choice of solutions to clients on how they want solutions/ products to be designed, monitored and controlled. 'Compiling data, technology application and analysis, writing up a report are secondary, but formulation and negotiating a strategy to articulate logically the best business choices becomes primary', a CIO concludes.

The e-leaders are not necessarily experts in technology, with hands-on skills in technology or business, but they must be independent learners and thinkers with hybrid skills. The combination of management, market, ICT and industryspecific skills are seen to be essential for 'hybrid e-leaders' who could take more responsibility and be ready to lead organisational change and practice. Both knowledge and personality drive e-leaders to keep learning and to lead change. A CEO from an SME in software says, 'effective e-leaders get creative at work, find solutions, expertise, knowledge, remain alert at all times, thinking, who can they talk to as customers?'. 'This is something like "magic dust" - a combination of skills, experience and teamwork that enables innovation and creative solutions', the CEO of an SME in IT solutions added. Therefore we propose:

Proposition 2: Hybrid skills facilitate strategy execution alignment through better exploiting new technologies and embedding them into the organisation and its business activities. This constitutes e-leadership in terms of embracing business strategy and IT skills, according to need, in order to exploit IT and to respond rapidly to market changes, digital patterns and new business opportunities.

A proper architectural view was also identified as an important part of e-leadership, providing an overarching blueprint of the structure and operation of SMEs and their external partnerships, enabling SMEs to most effectively achieve their objectives with limited resources. It was recognised by the interviewees that a leader's architectural view facilitates strategy execution and technology transformation alignment, where design logic and process arrangement, skills, organisational and systems architecture supporting the realisation of business and IT vision are provided.

In the interviews, 20 managers of SMEs stated that architectural views on workforce management and partnership building are important for e-leadership. An architectural view is recognised as an important aspect in an SME, while a proper strategic alliance mechanism will help in gaining knowledge and expertise. Alliances or joint ventures, where SMEs and collaborators jointly develop organisational and IS infrastructure, appear to be an effective approach in helping SMEs to support business strategy and competitiveness. For example, an SME in an IT services exchange shared
IS infrastructure with a knowledge service provider through a joint venture. Each complemented each other's capabilities in building up value and IS architecture where the joint venture produces more value than a single SME with limited resources. A majority of SMEs had formed alliances with external partners, especially where architectural issues were considered important. An architectural view was considered by many e-leaders (either in IT or non-IT sector) as an effective way to build up business competence. The combination of IT architecture (technologies, functions, hardware, and data communications) and organisational architecture (organisational structure and processes on top of the IT architecture) will inform what is needed and how they work together to support business strategy.

Therefore an architectural view helps SMEs to forge a value network with the necessary expertise. A number of applications in areas such as production, supply management, sales and customer management, and data management (engineering, entitlements, supply management, contract enforcement, supply and data management) cover an array of complex inter- and intra-organisation relationships. e-Leaders' architectural views will guide the formation of each relationship within and outside SMEs. For example, a software SME runs its business through project developers (project sponsor) with an IT team, working together, both within the SME and with external partners. The e-leader, working with the CEO, created an architectural portfolio including business applications, data architecture and technical infrastructure and personnel related to the project. The method of collaboration is then developed according to the architectural view of the project, on what is needed and how the internal team and external partners work together. Therefore we propose:

Proposition 3: An architectural view facilitates strategy execution and technology transformation alignment. It constitutes e-leadership by providing a design logic and arrangement in value, process, skills, organisational and systems architecture that supports business and IT 'alignment and strategy achievement'.

Qualities in competitive potential alignment

While agile leadership, hybrid skills and an architectural view are recognised as important e-leadership constructs in strategy execution and technology transformation alignment, digital entrepreneurship was identified by interviewees as a key construct in competitive potential alignment. Digital entrepreneurship here refers to the establishment of a new organisation, as well as the growth of an existing organisation that relies on ICT for its operations and/or its products and services through the inspiration of human assistance and use of ICT. Interviewees from 10 SMEs pointed out that digital entrepreneurship facilitates identification and interpretation of trends in the IT environment helping firms to articulate how the emerging IT competences would impact on business strategy.

In particular, innovative uses of existing technologies are recognised as one aspect of digital entrepreneurship that can improve business competence. The CIO of an aerospace SME pointed to the future incorporation in IT strategy of mobile technology, applications and the internet of things with existing technology competences. The combination of 
technologies and the role of digital entrepreneurship in business strategy were alluded to by the CEO of a broadcasting SME. He stated, 'digital entrepreneurship and innovation may involve up to 75 to $80 \%$ of the total budget. This cost is split across application development, operations, maintenance and customer intimacy technologies involved in the innovation cycle'. The same strategy has been alluded to by other CIOs and CEOs of SMEs operating in both IT and non-IT industries. Therefore we propose:

Proposition 4: Digital entrepreneurship enables competitive potential alignment. It constitutes e-leadership by facilitating the identification and interpretation of trends in the IT environment, enabling articulation of how emerging IT competences inspire business innovation.

Creating competitive value using digital technologies was also mentioned by interviewees, referring to creating 'tomorrow's value' by reconfiguring the value chain and creating new ecosystems and markets. The empirical data (from 23 SMEs) suggests that the leader as a value creator plays an important role in competitive potential alignment, in particular exploiting digital technologies to impact on new products and services, influencing key elements of strategy and developing new value propositions.

It would appear from the interviews, that using data is one of the major ways of creating competitive value. Data analytics on market and customer information was identified as an important technology competence serving to create value. It enabled collection, processing and analysis of large sets of data supporting key decisions such as market positioning. A business intelligence SME identified the innovation to build up business competence using data analytics. The SME built a mobile app to access the quality of performance of automotives for car dealers all over the world. Using existing big data analysis including data from Facebook, Twitter and other social media, the application assists business managers to understand potential opportunities and threats in the automotive market.

A CIO from an aerospace and defence SME mentioned, 'Our business competitiveness is predicated on providing the right data at the right time to enable our customers to make the right decisions. Our business competence closely relies on the combination of software and data analytics technologies that support customers' business processes'. This SME aggregates a large set of airlines' data. They provide this information to their customers (airlines) as a service helping them with customers' supply management and contracts improving efficiency and lowering costs. In this case, IT competences and their orchestration collectively provide powerful support for their business scope and competence. The CIO says, 'we hold a unique position in the industry and are regularly acknowledged in the press by customers. To maintain this position, we continuously need to update our technology competence and refine IT strategy to create more value, especially in the information-rich digital age'. Therefore we propose:

Proposition 5: A competitive value creator facilitates competitive potential alignment. This constitutes e-leadership by exploiting digital technologies to impact new products and services, an influential key attribute of strategy and creating new competitive value.

\section{Qualities in service-level alignment}

Although being a digital entrepreneur and value creator is essential for e-leaders to drive competitive potential, being a value protector was identified as the basic requirement for e-leaders to keep up to speed and not lag behind competitors through the use of technologies. The value protector refers to the ability to ensure that IT infrastructure could enhance internal and external processes supporting SME's operations and core capabilities across the whole value chain. It is defined as executive leadership enabling the internal service business to succeed through ICT support. It was pointed out by the interviewees that a value protector enables service-level alignment where an internal-service business succeeds through digitisation.

One of the basic requirements for e-leadership was identified as the effective use of technology to optimise organisational and IS infrastructure. The aim is to enhance the daily operation of SMEs. A CIO from a financial information SME stated, 'IT is used to increase production and to improve operation excellence. It improves the core processes for production through computerised processes. IT also enhances the connection with customers, increases the quality of customer service with better responsiveness (e.g. Facebook, Twitter and Salesforce software to exchange experiences, receive and respond to comments)'. This is how the IS infrastructure optimises the production process and 'speaks' to customers. Another example is a financial service SME that applies computerised processes of e-billing supporting their clients' business processes. Its CEO stated, 'Technology is used to increase efficiency and reliability in operational and administration processes in the enterprise and for clients. It increases flexibility and responsiveness and contact with customers in order to support the operations for core capabilities of our organisation. All members of our company are using their IT and business expertise to deliver $100 \%$ service in time through our IS infrastructure - this is how we optimise our operation in this digital age'. Therefore we propose:

Proposition 6: A value protector facilitates service-level alignment. This constitutes e-leadership in optimising processes and services across the value chain through using data, digitising core business and allocating limited resources.

\section{The development of an e-leadership model for SMEs}

In addition to the six aspects of e-leadership discussed, we further synthesise the empirical findings into detailed characteristics of e-leadership based on the concepts of agile leadership, hybrid skills, architectural view, digital entrepreneurship, competitive value creating and value protecting. We define and describe 16 constructs that constitute the six aspects and conclude this section by proposing the e-leadership model (Figure 3) and propositions for how the constructs contribute to different aspects of e-leadership.

\section{Agile leadership}

In many cases, interviewees declared that leaders need to be agile themselves but, more importantly, able to promote/ enhance the agile culture in the organisation. The agile culture deprecates tightly defined roles, stresses teamwork and 
continuous improvement, and demands constant close communication with customers (BCS, 2015). A CEO from consumer goods and retail commented, 'Our business partners now demand agile IT responsiveness because the markets they serve place similar demands upon them'. New technologies increase the speed of information exchange and communications. Particularly in the digital age, the leadership agenda will be dominated by this simple ultimatum - agility or redundancy, be quick or die. The primary measure of a leader's success, in addition to the price and reliability of a product, will be the speed of service delivery and the 'ability to foresee customer preferences, often identified through talking effective communication with customers', added a CEO of a trading service. The empirical evidence from the interviews confirms that the most influential attribute and trait of a successful leader is an ability to change and control the organisational and professional attitude in facing digital and business opportunities. Therefore we propose:

Proposition 7: Agile culture is important in e-leadership for leaders to build vision, belief and attitude in the organisation towards agile response in a changing business and digital environment.

While agile culture enables change of mindset, agile strategy is important in making changes happen in order to realise business value through technologies. According to the empirical evidence, agile strategy for e-leadership is the approach of prototyping business strategy with digital vision in order to identify value pools. Agile strategy is likened to an experimental journey to rapidly test and define products and approaches and then scale what works with iterative deployment. Eleven out of 42 interviewees emphasise that in a competitive landscape, and to enable this journey, leaders should have an agile prototype strategy including clear vision and KPIs, priorities, investments and governance in order to regularly review and adjust business and digital strategy. Therefore we propose:

Proposition 8: Agile strategy enables leaders to prototype/ implement business and digital strategies in order to realise business value in an agile way.

In addition to agile culture and strategy, pro-activeness to achieve readiness with adequate capabilities is important in facing a new and changing digital environment. Pro-activeness in both business and IT infrastructure was mentioned by respondents from 15 organisations as an important factor for strategy execution. This pro-activeness means that, instead of passively adapting organisational and IT infrastructure to maintain the status quo, e-leaders should deploy foresight attempting to foresee changes in the business environment, mainly driven by markets and customers, and respond strategically. One senior manager from a finance SME mentioned that, "lack of urgency and slow response to business ecosystem changes, is one of the main threats to competiveness in the digital age'. A CEO from service consulting commented that, 'It's all about capability. Don't be a kid in a sweetshop! Looking at new technology features makes us feel excited. New features are only useful if they deliver a benefit. It's a simple concept, sometimes hard to achieve, rarely done'. Seventeen interviewees in our study came up with the importance of pro-activeness by managers, in relation to the
SME's readiness in both human and IT systems, to building their company's future strategy. This was thought to include process re-engineering, architecture development and development of employee skills, investing in employees' further IT and business education and training offsite, participating in open knowledge-exchange events (e.g., conferences, workshops, industrial exhibitions and fairs). This pro-activeness to new technology coming from both middle and top level managers is needed and was mentioned by 17 out of 42 interviewees. The ability of IT, business and marketing specialists, as well as other managers to be pro-active and respond rapidly and efficiently to market demands through an increase in the processes of interaction between humans and technology could be termed 'e-readiness'. e-Readiness should be a fundamental part of strategy rather than a bolt-on option or afterthought, because agility will not come if IT departments are overreliant on software code engineering. Therefore we propose:

Proposition 9: Leaders' pro-activeness determines an SME's capability in both business and IT to respond rapidly and efficiently to market demand.

\section{Hybrid skills development}

Role shifting management was recognised by interviewees as an important means to develop hybrid skills. New disruptive technologies challenge managers' skills, but also create opportunities in terms of new roles and responsibilities. For example, 'the marketing manager is now taking care of cloud and information sharing between customers', stated a trading services CEO. Role shifting management entails management helping, incentivising and rewarding employees to change role, for example, from IT specialist roles to business related roles and vice versa. Twenty out of 42 interviewees pointed out that role shifting was an important contributor to flexibility and broadening firms' cognitive boundaries. Role shifting may take place from one day to a week; it could involve individuals or teams. A CEO from the manufacturing sector stated that, 'we do need more technology specialists, but we are also desperately short of other IT skills, such as business analysis, big data, project and programme management, technology risk management and IT-enabled change management. These are essential to support the shift to true digital operation'.

There is a clear message from our empirical data that SME leaders need to drive IT professionals to be business savvy and vice versa. This can help to 're-plumb' the business, and so to maximise the potential of existing and new technologies to improve company competitiveness, customer service, efficiency, productivity and innovation. It requires IT professionals to be able to bridge the gap between technology and customer needs, between technology and human resource management, technology and e-readiness, technology and recognition of opportunities and leveraging threats and, finally, technology and creativity. Technology leaders (e.g., CIOs) feel an ever-increasing need for 'softer' skills, for example, negotiation and decision making, which are necessary to influence board level members and their decision making. SME leaders are calling for specific lifetime learning and further education programmes (e.g., one-day business workshops, executive education) that are central to business change in organisations. Without role shifting and 
cross-disciplinary skills, opportunities might be missed and, more likely, technologies will become a 'bolt-on' to existing working practice instead of being a strategic weapon to leverage investment benefits and minimise losses. The empirical evidence reveals that role shifting management will forge intelligent links between IT specialists on one side and business and market specialists on the other. In the digital age this ensures that IT is better understood and aligned, especially in the step change from old to new ways of working and leading. For example, an automotive consulting CEO mentioned that, 'New employees will be doing client presentations for consulting projects, but they'll also be debugging a software setup. Their skills will be further enhanced by "practice" towards solution experts in certain subject areas combined with more industry-specific skills. Their job is exactly to bring the business side of things and the scientific processes into our technology solutions and provide the best combination of the two'. Therefore we propose:

Proposition 10: Role shift management facilitates the development of hybrid skills - business, IT and crossdisciplinary skills - allowing business and technologies to be better understood, exploited and aligned.

\section{Architectural view}

Architectural workforce management refers to the landscape and architectural vision to build up human capital to provide the requisite infrastructure and expertise. It was mentioned by interviewees that the proper architectural view on organisational expertise is important for building up both business and IT infrastructure considering the resource constraints that challenge most SMEs. A CEO from the manufacturing sector commented, 'SMEs face harsher choices in terms of sourcing their needed e-leadership skills. Given our limited resources, we will have to be careful and invest well in the priority skills most functional to our business model'. Leaders need to either rely on external service providers or hire new resources or train existing staff, but need an architectural vision to identify what combination of expertise will drive optimal technological capabilities. A point supported by Keen and Williams (2013), stating that IT is a hub for contracting relationships and enabling the source of human capital upon which the firm can draw. IT needs a new style of talent chain and partner chain management. A COO from utilities and energy mentioned, 'Our organisation operates on a lean staffing model, with skills augmented from external service providers. The model envisages the system landscape and architecture to be designed inhouse and bringing in external suppliers to provide the requisite infrastructure and applications'. Therefore we propose:

Proposition 11: Architectural workforce management is important to a leader's architectural view in order to identify the combination of expertise that drives optimal business and technological capability.

In addition to the architectural view on the workforce, external partnership through value architecture was another important issue alluded to by interviewees. Alliance architecture refers to the architectural view aiming to identify an appropriate approach to forging inter- and intra-firm relationships taking into account what is required and joint working methods in a digital value chain. Keen and Williams (2013) highlight the need for value architecture aligned with the needs of business built on digital opportunity. Our data supports this notion as 14 respondents suggested that the most fundamental opportunity for IT is to recast the discussion of cloud computing and managed networks, to consider such investments as variable rather than fixed cost, and take into consideration its intangible relation-building potential. When digital intensity increases and digital business strategy takes hold, improving business competiveness for SMEs is more likely to be based on alliances and partnerships through shared digital assets with other firms in the business ecosystem across different traditional industry boundaries. Increasingly, leaders need to build digital alliances with different firms to pull together the requisite scale and resources in areas where they do not see competitive advantage. Therefore we propose:

Proposition 12: Alliance architecture plays an important role in a leader's architectural view identifying an appropriate way to forge inter- and intra-firm relationships in the digital value chain.

\section{Digital entrepreneurship}

Digital entrepreneurship requires a new type of e-leader who acts as the innovative disrupter. Innovative disrupter refers to a person who unravels the complexity of IT, increases accessibility to technology and is open to new ideas, with the ability to work with peers on getting the right things done. The empirical evidence from 12 organisations supports the view that disruptive innovation is required to drive the business vision of the top management team, to think outside the box and to envisage new scenarios for digital business across firms and industries. A CEO from ICT services and consultancy commented, 'We need to leverage the company's resources and capital, not just react to technology disruption but rather to embrace and interweave digital technologies throughout our company to drive the disruptions ourselves and gain advantage'. The potential lies in creativity in recreating and redefining business model to create competitive advantage. Therefore we propose:

Proposition 13: Being an innovative disrupter is important in a leader's digital entrepreneurship, to be open to new ideas of competitive digital business.

In addition to innovative disrupter, the culture and mindset of the digital entrepreneur were recognised as further traits of e-leaders. The interviewees highlighted that the CIOs, especially in non-ICT firms, for too long have been identified as the strategic and commercial weak link rather than people adding tangible value across the business. A CIO from financial services commented that, 'It is important to have the digital entrepreneurship culture that thinks collectively, understands how best to resolve the issues that matter across the business and ultimately delivers commercial value'. A CEO from the retail industry also mentioned, 'It's a complete change of mindset. It's understanding that no "corporatecourse" is going to save you. It's up to individuals to not just be digital savvy, but to gain experience through their own endeavours and to keep learning, or get out the game'. 
Skills and attitude is the third aspect of digital entrepreneurship contributing to SMEs e-leadership. The following digital skills were recognised by eight interviewees as important: design thinking, software programming, creative problem solving, UX design, lean start-up and continuous deployment, building functional prototypes, fundraising, metrics framework and continuous testing, customer acquisition and pitching. However, the interviewees also pointed out that, 'successful e-leaders do not necessarily possess all these skills. Skills can be learned but attitude is revealed and polished', commented an ICT services CEO. Successful digital entrepreneurs are recognised as having the following attitudes: resilience to adapt to stressful situations or crises (because of attendant risks inherent in new ideas); agility (knowing when to pivot is an art); enthusiastic and passionate about sensing, serving and satisfying customers; and engages the entire workforce to deliver exceptional results for all stakeholders. Therefore we propose:

Proposition 14: Culture, mindset, skills and attitude play an important role in inspiring and engaging the organisation towards innovation and digital entrepreneurship.

\section{Competitive value creator}

Interviewees indicated that prioritisation of resources supported by integrated ICT is important in creating competitive value. This is similar to the point made by Henderson and Venkatraman (1993), pointing out that top management need to act as the prioritiser allocating scarce resources. Empirical evidence points to prioritisation as a key skill. Tension between allocating resources to operations and innovation is a fact of life. A CIO from healthcare services brought this issue to life stating 'too much time spent "keeping the lights on" and not enough time spent innovating'. The CIO of a manufacturing organisation commented, 'Leaders need to think about spending more time on making a tangible difference to the business rather than deploying resources on tedious low-level tasks. It will also enable a more comprehensive approach to innovation, driving greater potential value for the business'. Therefore we propose:

Proposition 15: Prioritising resources supported by technology can make a tangible difference to the business creating competitive value.

In addition to prioritisation, the ability of leaders to recognise and unlock the value of data was mentioned as another key contributor to creating value. Empirical evidence from ten SMEs supports the view that firms must start treating data more as a supply chain, enabling it to flow easily and usefully throughout the entire organisation - and eventually throughout the firm's ecosystem. CEOs need to find ways to better use internal and external data. Data is important internally, but firms must now realise that the value of data extends beyond a firm's boundaries. A CEO from utilities services commented, SMEs now have more potential than ever before to realise the true value of their data through forging new partnerships to creating new revenue streams, or even entering new markets. Moreover, SMEs using big data generate $12 \%$ higher revenues than those that do not experiment with big data. They are three times more likely than weak innovators to leverage big data mining for new project ideas and three times more likely to be actively targeting innovation towards digital design, mobile products and capabilities, speed of adopting new technologies and big data analytics (Fitzgerald et al., 2014). Digital offers SME leaders new opportunities to drive sustainable competitive advantage from data and to generate entirely new revenue streams, business units and standalone businesses by capitalising on the data they hold (Fitzgerald et al., 2014). SME leaders can take advantage of opportunities for data monetisation to sell data insights directly, share them through partnerships or develop entire ecosystems around them. Therefore we propose:

Proposition 16: Recognising and making full use of data throughout the firm's ecosystem is a key to creating competitive value.

\section{Value protector}

Interviewees pointed out that digitising the core business enables firms to better protect value. This quote from one of the respondents captures this point, 'Integrating technologies into core company processes provides opportunities for cutting cost, creating new services, exploiting new channels, increasing proximity between customer and team, and providing instant access to the market'. It is important to redefine the way in which services are delivered and consumed going forward. The SME leaders need to simultaneously embark on the digital transformation journey while maintaining everyday business. An executive from the education sector commented that, 'The most successful leader will run the business and transform it at the same time through better and simpler ways of consuming data, information, products and solutions as technology, and accessibility to it, improve'. Twenty organisations mentioned that leaders ought to be able to use technological competence and IT infrastructure to optimise internal processes for core operational activities. A CIO in transportation stated that, 'It is important to identify specific tasks within internal services to optimise the operational process and succeed within the operating guidelines through IT infrastructure (ERP, CRM and SCM)'. Another CIO from an ICT consultancy mentioned that, 'Integrating functions in IT infrastructure is a good way of effectively allocating resources to meet customers' requirements. By identifying where the delays and difficulties lie, the management team can then look at integration opportunities to optimise services'. Analysis of our empirical data reveals that there is an increasing need for technology capabilities to move at the same speed as the business and to make different systems talk to each other in order to optimise business processes. Therefore we propose:

Proposition 17: Digitising core business process enables digital transformation, maintaining and refining the route through which services are delivered and optimised.

Modularising and interfacing flexibility was recognised as another aspect of value protection. SMEs need to assess their unique drivers of advantage in digital settings, modularise their business processes and rely on plug-and-play capabilities for optimal linkage between digital assets. The empirical evidence revealed that many new start-ups rely on linkages through application programming interfaces and web services, 
validating a point made by Bharadwaj et al. (2013). Digital business is marked by innovation through interfaces - to customers, partners and suppliers. The IT architecture determines the platform for interfacing, and choices of technology and standards determine the degree of freedom of the business - its platform opportunities. For example, a business solutions company creates a plug-and-play modules platform because it operates in a constantly changing and expanding environment. So, instead of re-inventing the wheel for every solution created, it works with these flexible modules to increase efficiency and flexibility. Therefore we propose:

Proposition 18: Modularising and interfacing IS infrastructure is important for leaders to ensure flexibility in delivering service and value.

Digitalising business brings efficiency but also brings risks. Therefore, in addition to resilience in leadership attitude (referred to in the section 'Digital entrepreneurship'), mindset in system resilience is the new high ground for CIOs who take their strategic business roles seriously. The interviews revealed that a mindset rooted firmly in the context of business risk and a deep understanding of the constant threat of business disruptions - from hurricanes, hackers, or internal upgrades - and of the risks that those threats pose to maintaining operational continuity and brand value is required in protecting existing business value. Leaders are the ones who establish the resilience mindset and know that many of the tools and methods (e.g., agile) to engineer for resilience are available and are improving all the time. It was recognised by interviewees that it is neither simple nor cheap to provide real resilience. A mindset phasing in resilience over time, as business risk and process economics dictate, is needed. This requires the resilience mindset, as well as thinking ahead when the core business is digitised (e.g., cloud-based operations). Therefore we propose:

Proposition 19: A leader's mindset in resilience of IS infrastructure is important in protecting value from potential risks when digitising core business.

\section{Conclusions and future work}

This paper offers an insight into e-leadership for SMEs from both theoretical and practical perspectives. The existing e-leadership studies while helpful do not offer vigorous empirical evidence showing how e-leadership drives successful alignment between business and digital strategy. This is particularly pertinent as most SMEs are touched by the digital revolution. We adapted the strategic alignment theory to construct our e-leadership model advancing the current theoretical understanding of e-leadership, especially at the strategic and macro levels. The inductive phase of research was augmented by a deductive empirical testing of the veracity and applicability of the deduced e-leadership model. Hence practitioners will benefit because the proposed model enables leaders, drawing on the proposed e-leadership construct, to more effectively establish business and digital strategies. We explicitly address e-leadership from an e-leadership domain and capabilities framework, and identify essential e-leadership qualities, providing a powerful diagnostic tool.

We contribute to the literature by developing a theoretical foundation for e-leadership drawing on the widely accepted strategic alignment theory. Moreover, we extended the alignment perspective linking e-leadership domains and capabilities to the strategic use of digital technologies. e-Leadership at the strategic level is therefore theoretically grounded through our study as the critical decision domains and capabilities for driving effective alignment among business and digital strategies, and also the infrastructure. More specifically, these capabilities provide a theoretical e-leadership framework that examines a leader's role from both the business strategy driven perspective (strategy execution and technology transformation) and the digital technology enabling perspective (competitive potential and service delivery).

Furthermore, apart from the general theoretical capabilities, our research identified e-leadership qualities and detailed constructs that are strongly supported by empirical evidence and are specific to SMEs. The mapping between e-leadership capabilities and empirical constructs is shown in Table 3. Six major SME e-leadership qualities are identified based on the experience of successful SMEs, though none of them have been explicitly investigated and systematically organised as e-leadership features in previous research. Specifically, three of the e-leadership qualities, namely, agile leadership, architectural view and digital entrepreneurship were mentioned by a majority of interviewees. Even though these concepts are not new and are popular in other areas of research, this is the first time that these constructs have been incorporated with a strong empirical grounding in the e-leadership concept. We found that agile leadership (agile culture, strategy and pro-activeness) are particularly important for SMEs to quickly execute business strategy linked with digital technologies in the ever-changing market. The architectural view is also found to be an important quality of e-leadership. It transforms technology and organisational infrastructure into a collaborative platform for optimised human capital management and external alliance, given the limited resources of SMEs. Finally, we found digital entrepreneurship to be the key leadership mechanism especially when digital technologies are used as the enabler to inspire business innovation.

We maintain that our research will help e-leaders to assess leadership and management in the digital age. Practitioners such as entrepreneurs and SME leaders will benefit from this model by diagnosing and guiding their leadership towards business competitiveness. The empirical findings that underpin the e-leadership model provide a more comprehensive view of e-leadership in SMEs. Before offering our suggestions for future research we acknowledge a few limitations. The general applicability of our results may be limited as the qualitative approach was based on sampling only in four European countries. However, SMEs involved in this study represent a trend of economic development in other European countries and even provide an extremely useful indication to countries outside Europe. In constructing the e-leadership model, efforts have been made in benefiting from theoretical work and experience from outside Europe. While acknowledging that our results must be tested on a larger sample, we believe that the model developed offers a promising basis for future research on e-leadership, not only for SMEs but also for larger organisations.

We propose that future research activities should comprise testing of our model by means of a large-scale quantitative 
Table 3 e-Leadership capabilities and the mapping with constructs of SMEs

\begin{tabular}{|c|c|c|c|}
\hline Domains of decision making & e-Leadership capabilities & e-Leadership qualities in SMEs & e-Leadership constructs in SMEs \\
\hline Strategy execution alignment & $\begin{array}{l}\text { Strategy formulator to articulate the logic and } \\
\text { choices pertaining to business strategy } \\
\text { Strategy implementer to design and implement the } \\
\text { required IS infrastructure and processes that } \\
\text { support the chosen business strategy }\end{array}$ & $\begin{array}{l}\text { - Agile leadership } \\
\text { - Hybrid skill development } \\
\text { - Architectural view }\end{array}$ & $\begin{array}{l}\text { - Agile culture, strategy, pro-activeness } \\
\text { and e-readiness } \\
\text { - Role shifting management; ICT, } \\
\text { business, marketing and cross- } \\
\text { disciplinary } \\
\text { - Human capital management; strategic } \\
\text { partnership }\end{array}$ \\
\hline Technology transformation alignment & $\begin{array}{l}\text { Technology vision to support the chosen business } \\
\text { strategy } \\
\text { Technology architect to design and implement the } \\
\text { required IS infrastructure consistent with IT vision }\end{array}$ & $\begin{array}{l}\text { - Architectural view } \\
\text { - Digital entrepreneur-ship }\end{array}$ & $\begin{array}{l}\text { - Human capital management; strategic } \\
\text { partnership } \\
\text { - Disrupter and innovation; culture and } \\
\text { mindset; skills and attitude }\end{array}$ \\
\hline Competitive potential alignment & $\begin{array}{l}\text { Business visionary to articulate how the emerging } \\
\text { IT competences and governance patterns would } \\
\text { impact on business strategy } \\
\text { Catalyst to identify and interpret trends in the IT } \\
\text { environment to assist the business managers to } \\
\text { understand opportunities and threats from an IT } \\
\text { perspective }\end{array}$ & $\begin{array}{l}\text { - Digital entrepreneur-ship } \\
\text { - Value creator }\end{array}$ & $\begin{array}{l}\text { - Disrupter and innovation; culture and } \\
\text { mindset; skills and attitude } \\
\text { - Prioritisation; data-oriented value; } \\
\text { platform building towards eco-system }\end{array}$ \\
\hline Service-level alignment & $\begin{array}{l}\text { Prioritiser to articulate how best to allocate scarce } \\
\text { resources both within the organisation and in the } \\
\text { IT marketplace } \\
\text { Executive leadership to make the internal service } \\
\text { business succeed within the operating guidelines } \\
\text { from top management }\end{array}$ & - Value protector & $\begin{array}{l}\text { - Modularisation and flexibility; } \\
\text { resilience; digitalise core business }\end{array}$ \\
\hline
\end{tabular}


study that includes structural equation modelling. This would involve testing and further exploring the e-leadership model in finer detail with regard to e-leadership morphologies in different maturity stages of organisations by means of a large-scale qualitative study (e.g., at least 1,000 surveys). This large-scale data collection and analysis will produce a deeper understanding of how the various factors relate to one another in an integrated model with a dynamically evolving perspective of the organisation.

\section{References}

ACCA (2012). High-growth SMEs: understanding the leaders of the recovery. [WWW document] http://www.accaglobal.com/content/dam/acca/global/PDFtechnical/small-business/pol-tp-hgs.pdf (accessed 13 November 2014).

Akkermans, H. and van Helden, K. (2002). Vicious and Virtuous Cycles in ERP Implementation: A case study of interrelations between critical success factors, European Journal of Information Systems 11(1): 35-46.

Al-Mashari, M., Al-Mudimigh, A. and Zairi, M. (2001). Realizing IT value: the case of enterprise resource planning, in IRMA conference (Toronto, Canada).

Al-Mudimigh, A., Zairi, M. and Al-Mashari, M. (2001). ERP Software Implementation: An integrative framework, European Journal of Information Systems 10(4): 216-226.

Anyadike-Danes, M., Bonner, K. and Hart, M. (2011). Job creation and job destruction in the UK 1998-2010. Report, London: Department for Business Innovation and Skills.

Anyadike-Danes, M., Hart, M. and Du, J. (2013). Firm Dynamics and Job Creation in the UK: Taking Stock and Developing New Perspectives (No. 0006). University of Warwick, UK: Warwick Business School, Enterprise Research Centre.

Arham, A.F., Boucher, C. and Muenjohn, N. (2013). Leadership and Entrepreneurial Success: A study of SMEs in Malaysia, World 3(5): 117-130.

Armstrong, C.P. and Sambamurthy, V. (1999). Information Technology Assimilation in Firms: The influence of senior leadership and IT infrastructures, Information Systems Research 10(4): 304-327.

Avolio, B.J. and Gardner, W.L. (2005). Authentic Leadership Development: Getting to the root of positive forms of leadership, Leadership Quarterly1 6(3): 315-338.

Avolio, B.J., Kahai, S. and Dodge, G.E. (2001). E-leadership: Implications for theory, research, and practice, Leadership Quarterly 11(4): 615-668.

Avolio, B.J. and Kahai, S.S. (2003). Adding the 'E' to E-leadership, Organizational Dynamics 31(4): 325-416.

Avolio, B.J., Sosik, J.J., Kahai, S.S. and Baker, B. (2014). E-leadership: Reexamining transformations in leadership source and transmission, Leadership Quarterly 25(1): 105-131.

Avolio, B.J., Walumbwa, F.O. and Weber, T.J. (2009). Leadership: Current theories, research, and future directions, Annual Review of Psychology 60(1): 421-449.

Bardi, E., Raghunathan, T.S. and Bagchi, P.K. (1994). Logistics Information Systems: The strategic role of top management, Journal of Business Logistics 15 (1): 71-85.

BCS (2015). Digital leaders 2015 - Enhance your IT strategy. [WWW document] http://www.bcs.org/upload/pdf/digital-leaders-2015.pdf (accessed 13 July 2015).

Besson, P. and Rowe, F. (2012). Strategizing Information Systems-Enabled Organizational Transformation: A transdisciplinary review and new directions, Journal of Strategic Information Systems 21(2): 103-124.

Bharadwaj, A., El Sawy, O.A., Pavlou, P.A. and Venkatraman, N. (2013). Digital Business Strategy: Toward a next generation of insights, MIS Quarterly 37(2): $471-482$.

Bingi, P., Sharma, M.K. and Godla, J.K. (1999). Critical Issues Affecting an ERP Implementation, IS Management 16(3): 7-14.

Bloch, M., Blumberg, S. and Laartz, J. (2012). Delivering Large-Scale IT Projects on Time, on Budget, and on Value, McKinsey \& Company: Insight \& Publications. online publication October 2012.

Boynton, A.C., Zmud, R.W. and Jacobs, G.C. (1994). The Influence of IT Management Practice on IT Use in Large Organizations, MIS Quarterly 18(3): 299-318.

Bruque-Camara, S., Vargas-Sanchez, A. and Hernandez-Ortiz, M.J. (2004). Organizational Determinants of IT Adoption in the Pharmaceutical Distribution Sector, European Journal of Information Systems 13(2): 133-146.
Buchwald, A., Urbach, N. and Ahlemann, F. (2014). Business Value Through Controlled IT: Toward an integrated model of IT governance success and its impact, Journal of Information Technology 29(2): 128-147.

Cohen, J. and Schmidt, E. (2013). The New Digital Age: Reshaping the future of people, nations and business, UK: Hachette.

Coltman, T.R., Tallon, P.P., Sharma, R. and Queiroz, M. (2015). Strategic IT Alignment: Twenty-five years on, Journal of Information Technology 30(2): 91-100.

Davenport, T.H. (1998). Putting the Enterprise Into the Enterprise Systems, Harvard Business Review 76(4): 121-131.

Deloitte (2013). Doing Business in the Digital Age: The impact of new ICT developments in the global business landscape. Europe's vision and action plan to foster digital entrepreneurship, Brussels: European Commission, DG Enterprise and Industry.

Department for Business and Innovation \& Skills (2013). Business Population Estimates for the UK and Regions 2013. Statistical release London.

DeSanctis, G. and Poole, M.S. (1994). Capturing the Complexity in Advanced Technology Use: Adaptive structuration theory, Organization Science 5(2): 121-147.

Dong, L., Neufeld, D. and Higgins, C. (2009). Top Management Support of Enterprise Systems Implementations, Journal of Information Technology 24(1): $55-80$.

Ferneley, E. and Bell, F. (2006). Using Bricolage to Integrate Business and Information Technology Innovation in SMEs, Technovation 26(2): 232-241.

Fitzgerald, M., Kruschwitz, N., Bonnet, D. and Welch, M. (2014). Embracing Digital Technology: A new strategic imperative, MIT Sloan Management Review 55(2): 1-12.

Fox, S. and Amichai-Hamburger, Y. (2001). The Power of Emotional Appeals in Promoting Organizational Change Programs, Academy of Management Executive 15(4): 84-95.

Gartner (2010). Gartner Reveals Five Social Software Predictions for 2010 and Beyond. in Content and Collaboration Summit, London, UK: Gartner.

Ghobadian, A. and Gallear, D. (1997). TQM and Organization Size, International Journal of Operations \& Production Management 17(2): 121-163.

Ghobadian, A. and Gallear, D. (2001). TQM Implementation: An empirical examination and proposed generic model, Omega 29(4): 343-359.

Ghobadian, A. and O'Regan, N. (2002). The Link Between Culture, Strategy and Performance in Manufacturing SMEs, Journal of General Management 28(1): $16-35$.

Gilley, A., Gilley, J. and McMillan, H. (2009). Organizational Change: Motivation, communication, and leadership effectiveness, Performance Improvement Quarterly 21(4): 75-94.

Guimaraes, T. and Igbaria, M. (1997). Client/Server System Success: Exploring the human side, Decision Sciences 28(4): 851-876.

Gurr, D. (2004). ICT, Leadership in Education and E-Leadership, Discourse 25(1): 113-124.

Henderson, J.C. and Venkatraman, N. (1989). Strategic Alignment: A Framework for Strategic Information Technology Management. Working Paper No. 190, Cambridge, MA: Center for Information Systems Research, MIT.

Henderson, J.C. and Venkatraman, N. (1992). Strategic Alignment: A model for organizational transformation through information technology, New York: Oxford University Press.

Henderson, J.C. and Venkatraman, N. (1993). Strategic Alignment: Leveraging information technology for transforming organizations, IBM Systems Journal 32(1): 4-16.

Hernandez, M., Eberly, M.B., Avolio, B.J. and Johnson, M.D. (2011). The Loci and Mechanisms of Leadership: Exploring a more comprehensive view of leadership theory, Leadership Quarterly 22(6): 1165-1185.

Hirschheim, R. and Sabherwal, R. (2001). Detours in the Path Toward Strategic Information Systems Alignment, California Management Review 44(1): 87-108.

Holt, D., Armenakis, A., Field, H. and Harris, S. (2007). Readiness for Organizational Change: The systematic development of a scale, Journal of Applied Behavioral Science4 3(2): 232-255.

House, R.J. (1971). A Path-Goal Theory of Leader Effectiveness, Administrative Science Quarterly 16(3): 321-339.

Igbaria, M., Zinatelli, N., Cragg, P. and Cavaye, A.L.M. (1997). Personal Computing Acceptance Factors in Small Firms: A structural equation model, MIS Quarterly 21(3): 279-305.

Jung, D.I. and Avolio, B.J. (1999). Effects of Leadership Style And Followers' Cultural Orientation on Performance in Group and individual Task Conditions, Academy of Management Journal 42(2): 208-218. 
Kahai, S.S., Sosik, J.J. and Avolio, B.J. (2013). Effects of transformational leadership and media on collaboration and performance in virtual teams, in Symposium on Leadership in virtual groups: Looking back and charting paths forward; Orlando: Academy of Management meeting.

Ke, W. and Wei, K.K. (2008). Organizational Culture and Leadership in ERP Implementation, Decision Support Systems 45(2): 208-218.

Keen, P. and Williams, R. (2013). Value Architectures for Digital Business: Beyond the business model, MIS Quarterly 37(2): 642-647.

Kerfoot, K.M. (2010). Listening to See: The key to virtual leadership, Nursing Economics 28(2): 114-115.

Klein, K.J. and House, R.J. (1995). On Fire: Charismatic leadership and levels of analysis, Leadership Quarterly 6(2): 183-198.

LEAD (2014). E-Leadership Skills for Small and Medium Sized Enterprises project, European Commission, Directorate-General for Enterprise and Industry. online publication 15 July.

Loonam, J. and McDonagh, J. (2004). Principles, Foundations, and Issues in Enterprise Systems. Managing Business with SAP: Planning, implementation, and evaluation, London: Idea Group Publishing.

Lukács, E. (2005). The Economic Role of SMEs in World Economy, Especially in Europe, European Integration Studies 1(4): 3-12.

Malhotra, A., Majchrzak, A. and Rosen, B. (2007). Leading Virtual Teams, Academy of Management Perspective 21(1): 60-70.

Markus, L.M. and Tanis, C. (2000). The Enterprise Systems Experience from Adoption to Success, in R.W. Zmud and M.F. Price (ed.) Framing the Domains of IT Management: Projecting the future through the past, Ohio: Pinnaflex Educational Resources Inc, pp. 173-209.

McKenney, J.L., Mason, R.O. and Copeland, D.G. (1997). Bank of America: The crest and trough of technological leadership, MIS Quarterly 21(3): 321-353.

McKinsey (2012). The social economy: unlocking value and productivity through social technologies [WWW document] www.mckinsey.com/insights/ high_tech_telecoms_internet/the_social_economy (accessed 7 September 2015).

OECD (2010). High-Growth Enterprises: What governments can do to make a difference, OECD Studies on SMEs and Entrepreneurship. online publication doi:10.1787/9789264048782-en.

Orlikowski, W.J. (1992). The Duality of Technology: Rethinking the concept of technology in organizations, Organization Science 3(3): 398-427.

Orlikowski, W.J., Yates, J., Okamura, K. and Fujimoto, M. (1995). Shaping Electronic Communication: The meta-structuring of technology in the context in use, Organization Science 6(4): 423-444.

O'Regan, N. and Ghobadian, A. (2002). Formal Strategic Planning: The key to effective business process management? Business Process Management Journal 8(5): 416-429.

O'Regan, N. and Ghobadian, A. (2004). Leadership and Strategy: Making it happen, Journal of General Management 29(4): 76-92.

O'Regan, N. and Ghobadian, A. (2005a). Strategic Planning: A comparison of high and low technology manufacturing small firms, Technovation 25(10): 1107-1117.

O'Regan, N. and Ghobadian, A. (2005b). Innovation in SMEs: The impact of strategic orientation and environmental perceptions, International Journal of Productivity and Performance Management 54(2): 81-97.

Peppard, J. and Breu, K. (2003). Beyond Alignment: A Co-Evolutionary View of the Information Systems Strategy Process, in Conference on Information Systems: Seattle: ICIS Proceedings. 743-750.

Podsakoff, P.M., Ahearne, M. and MacKenzie, S.B. (1997). Organizational Citizenship Behavior and the Quantity and Quality of Work Group Performance, Journal of Applied Psychology 82(2): 262.

Purvis, R.L., Sambamurthy, V. and Zmud, R.W. (2001). The Assimilation of Knowledge Platforms in Organizations: An empirical investigation, Organization Science 12(2): 117-135.

Ramamurthy, K. and Premkumar, G. (1995). Determinants and Outcomes of Electronic Data Interchange Diffusion, IEEE Transactions on Engineering Management 42(4): 332-351.

Roberts, B., Jarvenpaa, S.L. and Baxley, C. (2003). Evolving at the Speed of Change: Mastering change readiness at Motorola's semiconductor products sector, MIS Quarterly Executive 2(2): 58-73.

Saldaña, J. (2012). The Coding Manual for Qualitative Researchers, London, UK: Sage.

Sarker, S. and Lee, A.S. (2003). Using a Case Study to Test the Role of Three Key Social Enablers in ERP Implementation, Information \& Management 40(8): 813-829.
Standish Group International Inc (2006). The Standish Group 2006 Chaos Report [WWW document] https://www.standishgroup.com/ (accessed 15 September 2015).

Umble, E.J., Haft, R.R. and Umble, M.M. (2003). Enterprise Resource Planning: Implementation procedures and critical success factors, European Journal of Operational Research 146(2): 241-257.

Vera, D. and Crossan, M. (2004). Strategic Leadership and Organizational Learning, Academy of Management Review 29(2): 222-240.

Vmware (2013). IT: time to take the lead in creating business value with enterprise social networks. White Paper. [WWW document] www.vmware.com/files/pdf/ socialcast/vmw-enterprise-social-network-value-whitepaper.pdf (accessed 7 September 2015).

Waldman, D.A., Ramirez, G.G., House, R.J. and Puranam, P. (2001). Does Leadership Matter? CEO Leadership Attributes and Profitability Under Conditions of Perceived Environmental Uncertainty, Academy of Management Journal 44(1): 134-143.

Watson, K.D. (2007). Remote management: traditional leadership behaviors in a contemporary work environment. Unpublished doctoral dissertation: Manhattan: Kansas State University.

Weick, K.F. (1990). Technology as Equivoque: Sense making in new techniques, in P.S. Goodman and L.S. Sproull (eds.) Technology and Organizations, San Francisco: Jossey-Bass, pp. 1-44.

Welsum, D. and Lanvin, B. (2012). E-Leadership Skills. Vision Report Brussels: European Commission.

Willcocks, L.P. and Sykes, R. (2000). Enterprise Resource Planning: The role of the $\mathrm{CIO}$ and its function in ERP, Communications of the ACM 43(4): 32-38.

Wymenga, P., Spanikova, V., Barker, A., Konings, J. and Canton, E. (2012). EU SMEs in 2012: at the crossroads. Annual report on small and medium-sized enterprises in the EU, 2011/12, Rotterdam: Ecorys.

Yin, R.K. (2009). Case Study Research: Design and methods, Thousand Oaks: Sage Publications.

Yoo, Y., Henfridsson, O. and Lyytinen, K. (2010). Research Commentary. The New Organizing Logic of Digital Innovation: An agenda for information systems research, Information Systems Research 21(4): 724-735.

\section{About the authors}

Weizi Li works as Lecturer in the Informatics Research Centre, within Henley Business School at University of Reading. Her research places an emphasis on co-design methodology for the alignment of service and technology and publications span from organisational semiotics, business process modelling, systems integration, systems architecture and health informatics.

Kecheng Liu, Professor of Applied Informatics, is Director of the Informatics Research Centre, within Henley Business School at University of Reading. He is one of the key figures in Organisational Semiotics internationally. His research interests and publications span from organisational semiotics, pervasive informatics, enterprise information management and intelligent systems.

Maksim Belitski is Lecturer at Henley Business School since 2014. He worked at Indiana University, University of Bolzano, Loughborough University, University College London, and University of Leicester. He is an expert in start-ups enterprises, creativity and innovation along with broader interests in entrepreneurship, leadership, regional economics and Institutions.

Abby Ghobadian is Professor of Organisational Performance and Head of Leadership, Organisations and Behaviour in 
Henley Business School. Abby's research interests lie in strategic management, organisational performance and leadership. He has widely published with more than 100 refereed papers in major journals and 7 research monographs, including a recent book entitled 'Strategic Management: The Challenge of Creating Value'.
Nicholas O'Regan is Professor of Strategy/Innovation and Enterprise in Bristol Business School at University of the West of England. He is the author of over 80 refereed papers, over 100 conference papers and co-author of books such as Strategy and Performance: Achieving Competitiveness in the Global Market Place, and Public Private Partnerships in Practice.

\section{Appendix A}

Table A1

Table A1 List of companies included in this study

No. Core products/services

1 Software system and web-based software platforms; training and consultancy for software solutions

2 Finance: consolidated electronic billing and payments, software solutions, consultancy and e-billing support

3 Houndit core modules, smart task for care, delivery, security and health; training and consulting

4 Software (market intelligence solutions; service smart; business management intelligence)

5 Beauty and fashion: advertisement, packages for SMEs advertising blogs and so on, and an online shop

6 Development technology for the central and local government (application for social care)

7 e-Education: educational platforms that enable faster communication Non- 9 in education

8 Finance: data support and information solutions for trading; trade data analysis and producing analytical reports

9 e-Health: mobile apps to treat anxiety and spider phobia

10 Film broadcast: advanced LED lighting technology and systems

Configure operation system to enforce policy; log management SIEM; configuration assurance

12 Airspace and defence: wide portfolio of services designed to deliver results in parallel to existing repair processes and systems

13 IT consulting: management consulting and information systems (Oracle)

14 IT consulting: SAP technology consulting business

15 Marketing services: digital marketing

16 Technology consulting services, systems integration and managed service providers

17 IT consulting: security area; data recovery services

ICT

Non- 100

ICT

ICT 3

Non- 7

ICT

ICT

ICT 16

ICT 20

Non- 120

ICT

ICT 32

ICT 215

Non- 10

ICT

ICT 20

ICT 12

18 Language training

Non- 30

ICT

19 Provision of computers, electronic and telecommunication services

ICT 97
20 Service: settlement of industrial assets through an online auction portal and reverse logistics

21 Service: platform of sale and purchase of tickets (events and performances)

22 Consumer goods and retail

Non- 17

ICT

Non- 250

ICT

Non- 50

ICT

23 Training services and education: learning solutions, areas of learning, (personal) development and communication

24 Business consultancy

Environment: nursery of trees; ground nursery (mostly for projects); container nursery (mostly to garden centres in Russia and Asia)

26 Facility management and real estate
Non- 45

ICT

Non- $<250$

ICT

Non- 49

ICT $\begin{array}{ll}\text { Interview role } & \text { Country } \\ \mathrm{CEO} & \mathrm{UK}\end{array}$

CEO

deputy $\mathrm{CEO}$

CEO

UK

IT director, UK

CEO

UK

Deputy CEO, UK

CTO

CEO UK

CIO UK

CEO UK

Deputy CEO, UK

CIO

$\mathrm{CIO}$

UK

CTO

UK

$\mathrm{CIO}$

Spain

CIO

CEO

Spain

CIO

Spain

$\mathrm{CIO}$

Spain

Informatics Spain

director

CEO

Spain

CIO Spain

Development Spain

director

Product

director

CEO

Spain

CEO

Spain

CIO The

IT manager The

Netherlands

Managin

Netherlands director

The 
No. Core products/services

27 A graphical company that provides a complete communications service to customers

28 Financial

29 Utilities and energy

30 Industrials and manufacturing

31 Services

32 Security solutions/services

33 Innovative lighting solutions

34 Sportswear, sport-lifestyle

35 Stevedoring, logistics

36 Online platform for apartment rental

37 Software development

38 Healthcare and home care

39 Healthcare

40 Financials

41 Utilities and energy

42 Industrials and manufacturing

\begin{tabular}{|c|c|c|c|}
\hline Sector & Employees & Interview role & Country \\
\hline Non- & & Management & The \\
\hline ICT & & director & Netherlands \\
\hline ICT & 230 & $\begin{array}{l}\text { Executive } \\
\text { manager }\end{array}$ & $\begin{array}{l}\text { The } \\
\text { Netherlands }\end{array}$ \\
\hline $\begin{array}{l}\text { Non- } \\
\text { ICT }\end{array}$ & 100 & $\mathrm{CEO}$ & $\begin{array}{l}\text { The } \\
\text { Netherlands }\end{array}$ \\
\hline $\begin{array}{l}\text { Non- } \\
\text { ICT }\end{array}$ & 250 & CTO,CEO & $\begin{array}{l}\text { The } \\
\text { Netherlands }\end{array}$ \\
\hline $\begin{array}{l}\text { Non- } \\
\text { ICT }\end{array}$ & 150 & CTO, CEO & $\begin{array}{l}\text { The } \\
\text { Netherlands }\end{array}$ \\
\hline $\begin{array}{l}\text { Non- } \\
\text { ICT }\end{array}$ & 30 & $\mathrm{CIO}, \mathrm{CEO}$ & $\begin{array}{l}\text { The } \\
\text { Netherlands }\end{array}$ \\
\hline $\begin{array}{l}\text { Non- } \\
\text { ICT }\end{array}$ & 23 & $\mathrm{CIO}$ & $\begin{array}{l}\text { The } \\
\text { Netherlands }\end{array}$ \\
\hline $\begin{array}{l}\text { Non- } \\
\text { ICT }\end{array}$ & 18 & CEO & Denmark \\
\hline $\begin{array}{l}\text { Non- } \\
\text { ICT }\end{array}$ & 130 & CEO & Denmark \\
\hline $\begin{array}{l}\text { Non- } \\
\text { ICT }\end{array}$ & 49 & $\mathrm{CEO}$ & Denmark \\
\hline $\begin{array}{l}\text { Non- } \\
\text { ICT }\end{array}$ & 15 & $\mathrm{CIO}$ & Denmark \\
\hline ICT & 86 & CTO & Denmark \\
\hline $\begin{array}{l}\text { Non- } \\
\text { ICT }\end{array}$ & 38 & $\mathrm{CEO}$ & Denmark \\
\hline $\begin{array}{l}\text { Non- } \\
\text { ICT }\end{array}$ & 45 & $\mathrm{CEO}$ & Denmark \\
\hline $\begin{array}{l}\text { Non- } \\
\text { ICT }\end{array}$ & 80 & CEO, CTO & Denmark \\
\hline $\begin{array}{l}\text { Non- } \\
\text { ICT }\end{array}$ & 180 & $\mathrm{CEO}, \mathrm{CIO}$ & Denmark \\
\hline $\begin{array}{l}\text { Non- } \\
\text { ICT }\end{array}$ & 30 & $\mathrm{CEO}, \mathrm{CIO}$ & Denmark \\
\hline
\end{tabular}

Source: European Commission e-Leadership Skills for SMEs (LEAD) project interviews

\section{Appendix B}

\section{Interview protocol}

Background and overview of the successful SME (about 1 page) Please note, before the interview, the interviewer may be able to gather much of the data for this section from the participating SME. In fact, it is strongly recommended collecting this as soon as possible, as these data are important for selecting the best candidates.

- When and by whom was the SME founded?

- Where is the SME headquartered? Does it have units elsewhere? (If so, when were they established?)

- How many employees are there in the firm (by year for the last 3 years)?

- What are the core products/services of the SME?

- In what sector does the SME provide those products/ services?

- Who are the customers of the SME?

- Who would say you are successful and why (name the 'well regarded third party')?
- Has the SME's growth in either employees or in turnover increased by $20+\%$ per annum for 3 years? (Please note: it is $\mathrm{OK}$ if the SME has not experienced such growth and the SME is well regarded by others as successful.)

Demand for e-skilled professionals (1-2 pages) Overall uses of ICT

- Overall, how is ICT used strategically in your organisation and who is responsible for those uses? Please consider processes related to the following strategic objectives:

- Production/operational excellence (e.g., using ICT to increase efficiency and reliability; low cost of operational and administrative processes)

- Customer intimacy (e.g., using ICT to increase flexibility and responsiveness, customer service, marketplace management)

- Product leadership/innovation (e.g., using ICT to create new products/services, enter new markets) 
- Is there an equivalent to a chief information officer - that is, someone who is responsible for orchestrating application development, operation and maintenance? Does your organisation have an informal or formal ICT or digitisation strategy? If so, what is it and how was it developed?

- How is total spending (capital plus operations excluding depreciation) on ICT distributed across these three areas (in terms of percentages)?

\section{Overall investments in ICT}

- Overall, during the past year, what percentage of the ICT budget was spent on any of the following ICT and uses of ICT? For each ICT that you relied on, please briefly explain for what purposes your organisation relied on it.

○ mobility and mobile apps development

- cloud computing

o data analytics (e.g., 'big data')

- social media technologies

o the internet of things (IoT) (incl. wearable computing)

\section{Roles and responsibilities}

- Overall demand

- How many FTEs or organisations does your organisation rely on for developing ICT applications? How many are long-term hires? Contracted for a specific period of time? External service providers?

- How many FTEs or organisations does your organisation rely on for operating and maintaining ICT applications and infrastructure? How many are long-term hires? Contracted for a specific period of time? External service providers?

- How many FTEs or organisations does your organisation rely on for using data to enhance operations, increase sales and/or improve the customer experience? How many are long-term hires? Contracted for a specific period of time? External service providers?

- Which skills were the most difficult to find? Why? Please consider the following technologies:

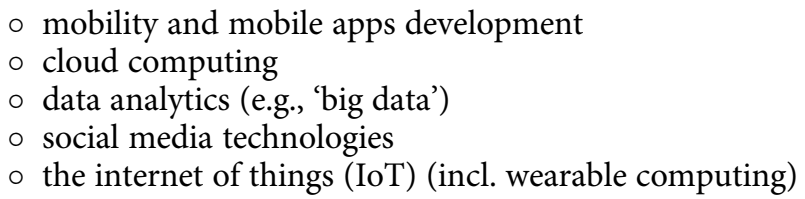

\section{Overview of a significant innovation from the past year (1-2 pages)}

- What was the most significant innovation that was realised during the last year? (Please note, it could have started several years ago; however, it needs to have been completed during the last year.) How did it add value to the SME? (e.g., enhance competitively customer service; significantly reduce operational costs)

- What was the process by which the innovation was developed?

- What role(s) did ICT have in the process? Did the innovation rely on any of the following ICT? If so, please explain, including the selection process:

- mobility and mobile apps development

- cloud computing

- data analytics (e.g., 'big data')

- social media technologies

○ the internet of things (IoT) (incl. wearable computing)

- Who were the key leaders involved in the innovation process responsible for managing uses of ICT? What did they do during the process?

- How did your firm obtain advanced ICT skills for using any of the aforementioned technologies? Was it difficult to find any advanced ICT skills? (If so, please explain)

- Did you rely on partners, consulting services or other external service providers to access the ICT skills needed for the innovation? (If so, please explain)

\section{Future demand for e-leaders}

- Over the next two years, what kinds of leaders does your organisation anticipate needing, with regard to using ICT to enhance its competitiveness?

\section{Engagements with educational institutions}

- Over the next two years, what kinds of training or education programmes would you wish for you and your staff?

- Has the firm engaged with any education institutions to address skills gaps?

- Do you use executive education?

- Do you use higher education (academic)?

- Do you use professional courses?

- In the future, would you invest in training to develop e-leaders? (Please explain)

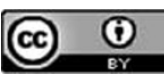

This work is licensed under a Creative Commons Attribution 3.0 Unported License. The images or other third party material in this article are included in the article's Creative Commons license, unless indicated otherwise in the credit line; if the material is not included under the Creative Commons license, users will need to obtain permission from the license holder to reproduce the material. To view a copy of this license, visit http://creativecommons. org/licenses/by/3.0/ 